\title{
Variety in founder experience and the performance of knowledge-intensive innovative firms
}

\author{
Ethan Gifford ${ }^{1}$ (D) $\cdot$ Guido Buenstorf $^{1,2} \cdot$ Daniel Ljungberg $^{1} \cdot$ \\ Maureen McKelvey ${ }^{1} \cdot$ Olof Zaring $^{1}$
}

Published online: 13 July 2020

(C) The Author(s) 2020

\begin{abstract}
This article contributes with an analysis of the specific linkages between knowledge, innovation and entrepreneurship for industrial dynamics, within the emerging literature upon knowledge-intensive innovative entrepreneurial (KIE) firms. We find a distinct variety in the usefulness of different types of founder experience (single or teams) in the performance of entrepreneurial firms. This variety affects selection in the economy, as measured by the performance of firms in a two-stage process - namely first by analyzing survival over time and then of high growth rates. We do so in order to consider averages/probabilities in the population using Cox regression as well as of the outliers, using quantile regression. We find that on one hand, founders having previously started firms or worked in the same industry are more likely to survive. On the other hand, very high-growth firms have founders who previously started firms or worked in universities. Combining different types of founder experience in KIE firms has a consistently positive relationship with performance both in terms of survival and of growth. Our interpretation is that the variety of founder experience affect selection processes and opportunity recognition in KIE firms and thereby fundamentally affect whether, and to what extent, entrepreneurial actions lead to industrial transformation.
\end{abstract}

Keywords Knowledge-intensive entrepreneurship · Firm growth · Founder experience

JEL classification $\mathrm{J} 24 \cdot \mathrm{L} 25 \cdot \mathrm{L} 26 \cdot \mathrm{M} 13$

Ethan Gifford

ethan.gifford@gu.se

1 Institute of Innovation and Entrepreneurship; Department of Economy and Society, University of Gothenburg, Viktoriagatan 13, 40530 Gothenburg, Sweden

2 Economic Policy, Innovation and Entrepreneurship Unit; Institute of Economics, University of Kassel, Mönchebergstrasse 17, 34109 Kassel, Germany 


\section{Introduction}

Neo-Schumpeterian innovation theories and evolutionary economics highlight the role of entrepreneurs as agents of change in the economy. Entrepreneurs act to not only exploit but also create innovative opportunities (Schumpeter 1934; Carlsson et al. 2013; Holmén et al. 2007); they tackle risk and uncertainty for the possibility of profits (Knight 1921; Fagerberg 2003); they create new knowledge over time which stimulates economic disequilibrium (Metcalfe 2002); and they further extend the cognitive base of the economy, which helps stimulate growth (Cantner et al. 2017). This article contributes with an analysis of the specific linkages between knowledge, innovation, entrepreneurship, and industrial dynamics, within the emerging literature on knowledgeintensive innovative entrepreneurial (KIE) firms.

The conceptualization of KIE firms is derived from research on Schumpeterian entrepreneurship, innovation systems and evolutionary economics (Malerba and McKelvey 2018a, c). Various strands of this literature postulate how and why knowledge and capabilities in general help these entrepreneurs innovate and compete (McKelvey and Lassen 2013; Malerba et al. 2016; Protogerou et al. 2017; Gifford 2017; Lassen et al. 2018), and researchers have begun to analyze specific relationships between different types of knowledge and performance.

Previous studies on the evolution of industries have highlighted the link between founders' pre-entry experience in the industry and the survival of their ventures (Audretsch 1991; Caves 1998; Geroski 1995; Klepper 2002, 2009; Klepper and Sleeper 2005). In this article, we expand this prior work by studying how various types of founder experience relate to the performance in a large sample of European KIE firms. Recognizing the limitations of survival as a measure of firm performance (cf., e.g., Lieberman and Montgomery 2013), we adopt a two-stage approach, first analyzing firm survival over time and then focusing on high-growth firms.

Entrepreneurship scholars have addressed a series of question about the relationship between the pre-entry endowments of founders and the performance of their firms (Brüderl et al. 1992; Gimeno et al. 1997; Parker 2004; Shane 2003; Helfat and Lieberman 2002). A meta-study by Unger et al. (2011) finds the human capital of founders and founding teams is influential for the success of new ventures in both high and low technology industries. Colombo and Grilli (2005) studied human capital in technology-based firms, finding synergistic gains from combining founders' economicmanagerial and technical education, in relation to experience from a specific industry. Other studies focus upon how founders' pre-entry endowments affect access to resources and their ability to manage the firm (Shane and Stuart 2002; Delmar and Shane 2004; Dencker et al. 2009), whereas some distinguish the origins of firms in terms of whether they are corporate or academic spin-offs and then analyze performance of that category of firms (Wennberg et al. 2011; Zahra et al. 2007). Going further, Buenstorf and Heinisch (2020) demonstrate that doctorate-holding inventors contribute to entrant performance, which indicates that only focusing upon academic entrepreneurship limits our understanding of startups' initial knowledge endowments.

Although the extant literature shows the importance of pre-entry endowments of founders, previous research tends to focus on particular types of entrepreneurial firms (e.g. academic or corporate spin-offs; technology-based firms), particular industry settings, or particular types of founder knowledge (e.g. education or previous industrial experience). As 
recommended by Agarwal and Shah (2014), we take a more encompassing approach; we develop a more fine-grained neo-Schumpeterian perspective on pre-entry endowment and the performance of knowledge-intensive innovative entrepreneurial firms.

Our article thus makes three contributions to the literature. First, we analyze a wide spectrum of types of entrepreneurial firms. KIE is an inclusive theoretical category. It denotes entrepreneurial firms that compete on the basis of various types of advanced knowledge and innovation, and which are found in low-, medium- and high-tech manufacturing as well as in services (Malerba et al. 2016). Based on previously established criteria (Malerba and McKelvey 2018a, b), we specify different degrees of knowledge intensity within this group of entrepreneurial firms, and analyze which types of founder and team knowledge are performance-relevant under which conditions. Specifically, our analysis focuses on three types of experience-based founder work knowledge: entrepreneurial experience, industrial experience, and academic experience.

Second, we analyze a large sample including more than 4000 firms from ten European countries, linking detailed survey data with longitudinal register information encompassing data on firm activity and financial performance. We also extend the existing literature on firm performance, which has mostly focused on single measures (mostly survival or some financial indicator; cf. Lieberman and Montgomery 2013), or, in the tradition of the rich theoretical studies of Penrose (1959) and Stinchcombe (1965), focus on those firms that experience exorbitant levels of growth, also called gazelles or high growth firms (Henrekson and Johansson 2009a, b). In contrast, we take a two-stage approach to analyze the performance of KIE firms. We first use Cox regression to assess the likelihood of survival in relation to founder knowledge. Although many firms survive, growth is much less a frequent occurrence. Therefore, in a second stage of analysis, we analyze growth conditional on survival employing quantile regression (cf. Coad et al. 2016; Czarnitzki and Delanote 2012). This allows us to obtain a fine-grained picture of the upper end of the spectrum of firm performance.

Third, our results demonstrate a distinct variety in the usefulness of different types of founder experience for the performance of KIE firms. On one hand, firms with founders who previously started firms or worked in the same industry are more likely to survive. On the other hand, high-growth outliers tend to have founders who previously started firms or worked in universities. This pattern indicates substantial heterogeneity in how the various types of founder experience affect selection processes that condition whether, and to what extent, entrepreneurial actions lead to industrial transformation.

The remainder of this article is organized as follows. In the next section, we outline our theoretical considerations, including a discussion of knowledge-intensive innovative entrepreneurship, and our hypothesized associations between founder experience and firm performance. This is followed by research methods, results, and finally, our conclusions and recommendations for future research.

\section{Theoretical considerations}

\subsection{Knowledge-intensive innovative entrepreneurship and firm performance}

We adopt the literature on the knowledge-intensive innovative entrepreneurial (KIE) firm as our theoretical point of departure. In this literature, KIE firms are defined as new 
learning organizations that use and transform existing knowledge and generate new knowledge in order to innovate within innovation systems (Malerba et al. 2016; Malerba and McKelvey 2018a, b; McKelvey and Lassen 2013).

KIE relates to and may encompass other prior conceptualizations concerning the blending of innovation, science, technology, and entrepreneurship. New technologybased firms (NTBF) is a concept that found prominence in the 1990s, and is still in use, which focuses predominantly on new firms in high-tech industries. This concept is quite broad in definitions and applications, and some studies give no explicit definition (cf. Yli-Renko et al. 2001; Löfsten and Lindelöf 2002). This arguably leads to problems in disambiguating the concept (Rickne and Jacobsson 1999). However, it is apparent that much of the NTBF-focused research also deals explicitly with firms that invent and use new technology and new ideas in high-tech industries. Other related concepts have since surfaced in the form of: Young Innovative Companies (YICs) (Schneider and Veugelers 2010), which refers to small, innovative and R\&D intensive firms, and; Innovative Entrepreneurship (Block et al. 2016) which focuses quite broadly on 'Schumpeterian' entrepreneurship. Under this classification, such entrepreneurs may be identifiable by willingness and ability to perform search activities to generate new opportunities (Wennekers and Thurik 1999; Block et al. 2016) and the entrepreneur mainly acts as the innovator (in a Schumpeterian sense). In our view, the concept of KIE encompasses the three prior mentioned classifications of entrepreneurial firms, but goes further in capturing important aspects of innovation, novelty and entrepreneurship.

KIE goes beyond looking at the entrepreneur or entrepreneurial firm as directly being, or employing, the inventor, and the firm may not directly be R\&D intensive in the traditional sense. Here the firm or entrepreneur may also be a user and/or applier of new scientific, technological and/or creative knowledge (McKelvey and Lassen 2013); Accordingly, KIE includes firms outside of high tech industries, which may be active in low- and medium-tech industries as well as the knowledge intensive business service (KIBS) sector. KIE moreover takes a more systemic perspective than alternative conceptualizations in terms of the role of the innovation in diffusing to other actors beyond the inventor or innovator. Recent literature on KIE has focused on a variety of questions about the relationships between knowledge, innovation, and performance (Gifford 2017; Lassen et al. 2018; Malerba et al. 2016; Protogerou et al. 2017). Yet few existing studies empirically analyze the link between different types of knowledge and firm performance. Prior research on KIE founders' experience in relation to survival and high growth rates has been scarce (Malerba 2010; Malerba et al. 2016). ${ }^{1}$ Given the lack of prior work specifically matching our conceptualization, below we mostly draw on the general entrepreneurship literature as well as studies on industrial dynamics and extend this work to KIE firms.

The general entrepreneurship literature has long argued that human capital plays a crucial role in the success of new ventures (Florin et al. 2003; Pfeffer 1994), as well as in the decision-making process leading to venture formation (Campbell 1995; Evans and Jovanovic 1989) and ultimately market exit (Gimeno et al. 1997). In this wider literature, human capital is tends to be proxied by years of schooling or the highest degree attained (Hitt et al. 2001; Kor and Leblebici 2005), but later research recommended against solely

\footnotetext{
${ }^{1}$ One exception is Lassen et al. (2018), which contrasts KIE firms in manufacturing versus creative and cultural industries.
} 
using such simplified proxies (Ployhart and Moliterno 2011; Unger et al. 2011). More broadly however, it has been shown that the human capital of founders and founding teams is influential for the success of a new venture in both high and low technology oriented industries, and more effective for younger as opposed to older firms. Human capital outputs (knowledge and skills) have a larger effect on success than human capital investments (mainly education) (Unger et al. 2011). In addition to the human capital inherent in founder's general knowledge, skills, and education, an important contribution to venture performance is made by earlier experience in starting a business (Agarwal and Shah 2014; Bosma et al. 2004; Klepper and Sleeper 2005).

We put forth that founder experience is derived from a variety of learning experiences, such as direct observation, participation, and developing practical skills and practices. Hence, the individual experience from starting other firms, working in the same industry, or working in universities tends to provide idiosyncratic sets of knowledge to founders. This variety of experience in turn affects the knowledge-intensity in the KIE firm in a way that matters to survival and high growth over time, which is indicative that the KIE can transform individual knowledge into organizational routines and capabilities (Helfat and Lieberman 2002). Such firm capabilities should also matter to absorb more knowledge, specifically in order to access and understand external sources of knowledge (Malerba 2010; Nelson and Winter 1982). As shown in Malerba and McKelvey (2018a), KIE firms are more dependent upon the innovation system than other types of entrepreneurial firms. Hence, we provide a specific interpretation of what types of founder experience are instrumental in determining the pre-entry resource endowments of a firm and how that firm performs in terms of survival and growth.

\subsection{Entrepreneurial experience}

Extant work on entrepreneurial experience has argued that founder human capital increases the probability of success of the venture through; increasing capabilities, entrepreneurial alertness, and exploitation of opportunities based on prior knowledge (Shane 2000); as well as attracting other sources of capital investment through a combination of simple and complex resources based on prior knowledge and experience (Brush et al. 2001). Dencker et al. (2009) investigated the mechanisms underlying the influence of pre-entry knowledge of new firms on their chance of survival in the long term, finding that prior related knowledge and management ${ }^{2}$ experience of founders increases survival rates through moderating the effects of early stage business planning. Founders tend to accumulate and build on this combination of knowledge and experience and use this learning to inform their subsequent business venturing. Existing literature also suggests that gazelles or high growth firms likely have a founder with entrepreneurial experience (Henrekson and Johansson 2009a, b).

Based on the extant literature, we can conjecture about the types of knowledge that experienced entrepreneurs have accumulated, as well as the types of opportunities they are more likely to identify and exploit when activating the accumulated knowledge. Doing so is helpful to form expectations as to how founders' prior entrepreneurial experience is likely to affect survival and growth of KIE firms.

\footnotetext{
${ }^{2}$ I.e. extent to which prior knowledge related to and affected entry-decisions; and, working in "a managerial capacity" (Dencker et al. 2009: 524).
} 
What distinguishes experienced entrepreneurs is their hands-on experience in running a newly established firm. Such startups are small, requiring the founder(s) to perform a wide variety of tasks (Lazear 2004). In addition, organizational routines are not yet strongly developed in startups, which complicates the prediction of behaviors of firm members (Nelson and Winter 1982) and contributes to the uncertainty faced by the firm leaders. Both these characteristics of startups provide for a rich learning environment, in which learning will tend to relate to diverse aspects of running a newly established firm, but the scope of specialization and acquiring in-depth knowledge about specific tasks is limited. We therefore expect that entrepreneurial experience endows founders with "baseline" knowledge and skills in running a newly established firm. This will increase the chances of survival for the new firm, as its founders can access a repertoire of experience-based skills allowing them to react to a wide range of problems that the firm may encounter. In contrast, given the limited scope for specialization and in-depth knowledge acquisition in startups, entrepreneurial experience may be less relevant in explaining high growth rates of KIE firms. Considering the role of entrepreneurial experience for the capacity of KIE founders to identify and exploit opportunities points to the same prediction. We expect that KIE founders with entrepreneurial experience are well-positioned to identify opportunities that "work" in the sense that their exploitation allows for building a viable business. However, there is no compelling reason why these opportunities should enable KIE founders to build a high-growth business.

These considerations inform our first hypotheses:

Hypothesis 1a: Having a founder with previous entrepreneurial experience will increase the likelihood of survival of KIE firms.

Hypothesis $1 \mathrm{~b}$. Having a founder with previous entrepreneurial experience will not lead to systematically higher growth rates in a surviving KIE firm.

\subsection{Industry experience}

Substantial prior evidence relates industry experience to new firm performance. Many of the respective studies investigate individual industries. A very robust finding in this line of research is that founders with intra-industry work experience, and particularly those who worked for top-performing industry incumbents, are associated with more successful ventures (e.g., Buenstorf 2007; Klepper 2002, 2009; Klepper and Sleeper 2005; Wenting 2008). Baptista et al. (2014) studied the effect of founder's backgrounds on new firm survival with a special focus on necessity vs. opportunity-based entrepreneurship. They found that industry experience of the founders had a positive impact on survival for opportunity driven entrepreneurs. Similar findings as in the single-industry studies have also been obtained for broader samples based on national register data (e.g., Eriksson and Kuhn 2006; Dahl and Sorenson 2014).

Klepper $(2001,2009)$ reviewed theoretical contributions pertaining to the nature, heritage and performance of (intra-industry) spinoffs, i.e. firms organized by founders with industry experience. The review indicates that strategic disagreements concerning innovation direction or market focus were instrumental in determining spinoff emergence as well as how spinoffs structured their own activities and how they performed (Klepper and Thompson 2010). This corroborates Boeker (1988) who suggests that founder experiences leave long lasting imprints on organizations. One limitation of 
much of the prior work on intra-industry spinoffs is that experienced entrepreneurs reentering the same industry are often included in the group of spinoff founders. In these cases, effects of industry experience cannot be disentangled from effects of entrepreneurial experience.

Studies focusing on categorizations such as new technology based firms and similar variants are also worth mentioning here, as there are some parallels to be drawn. Some such studies focused on linking specific skills generated prior to entry to improved post-entry performance outcomes (measured in rate of growth or changes in firm size over time) in NTBFs (Almus and Nerlinger 1999; Colombo and Grilli 2005). Colombo and Grilli (2005) notably found that prior industry experience of founders is positively associated with firm growth. Additional research has tested hypotheses regarding the effect of founder human capital on growth of these ventures, finding that founder's technical work experience in the same industry has both direct effect, as well as indirect effects as a conduit for obtaining venture capital, on NTBF growth (Colombo and Grilli 2010).

Again building on the prior literature, we can ask what kinds of knowledge prospective founders can acquire based on industry experience. Industry experience is clearly important to acquire knowledge about products, production technologies, and customer needs in the respective industry (Chatterji 2009). Entrepreneurs with industry experience tend to be specialists from the $R \& D$ or sales departments of industry incumbents. As highlighted by Klepper and Thompson (2010), differences in how they and the incumbent's managers interpret their specialized knowledge often provides the impetus for entrepreneurial activity. Depending on the prior position of the entrepreneur, the entrepreneurial opportunity they identified may be R\&D-driven (in terms of using new technologies) or use-related (in terms of serving new customer needs). Given the familiarity of the entrepreneur with the technology and/or the market, this opportunity may have a lot of potential. At the same time, the viability of the opportunity is often controversial (thus the disagreement with the prior employer) and accordingly its exploitation may be risky. This resonates with the finding from prior work that not all ventures started by individuals with industry experience are successful, but primarily those organized by founders leaving high-level positions at leading industry incumbents to pursue an opportunity they have identified on their prior job. We therefore expect substantial variance in the performance of firms with industry-experienced entrepreneurs. Specifically, while some of the high-growth firms in an industry may build on their founders' industry experience, on average there may not be a survival premium stemming from industry experience. We therefore predict the following:

Hypothesis 2a: Having a founder with previous same industry experience will not systematically increase the likelihood of survival of KIE firms.

Hypothesis $2 \mathrm{~b}$ : Having a founder with previous same industry experience will lead to higher growth rates in a surviving KIE firm.

\subsection{Academic experience}

Much of the research on academic entrepreneurship uses comparative studies to explore differences of academic spinoffs versus other types of entrants. For example, Criaco et al. (2013) found in their sample of Catalonian university spinoff NTBFs that having 
non-university human capital endowments negatively affected firm survival, while human capital endowments stemming from university environments and also entrepreneurship education endowments had a positive effect. However, other authors have found that the benefits from academic knowledge are less than those of having industry experience (Buenstorf 2007; Wennberg et al. 2011). Zahra et al. (2007) studied preentry knowledge conversion capabilities, using a three-stage concept including conceptualization, configuration and integration of new knowledge, and how these affected the post-entry performance of intra-industry vs. academic spinoffs. They found that intra-industry spinoffs benefit more from prior experience and connections, including resources transferred through founders and employees who previously worked at the parent organization, than academic spinoffs did. Clarysse et al. (2010) investigated the technological knowledge base possessed by corporate vs. academic spinoffs at inception and how this predicts firm growth. Their findings indicate that the impact of narrowly focused technology is important for corporate spinoffs, while broadly focused technology can have benefits for academic spinoffs, given that they can appropriately transfer the technology from the university to the firm by some means.

While their specific results differ, prior studies on academic spinoffs suggest that the founders of these firms have acquired knowledge that may be beneficial for the performance of their entrepreneurial ventures. It is plausible to expect that this knowledge mostly relates to the technological foundation of the new firm. In contrast, an academic background will often not provide entrepreneurs with in-depth knowledge about the market that their venture enters, and the entrepreneurial opportunity on which the venture builds will primarily of a technological nature. The lack of in-depth market knowledge is expected to turn the firms that academic entrepreneurs start into comparably risky ventures. At the same time, it is possible that the in-depth technological knowledge possessed by academic entrepreneurs enhances the growth potential of their firms (conditional on survival), as the broad and systematic knowledge based of the firm, possibly linked to collaboration with university partners based on the network that academic entrepreneurs have established prior to starting their firms, enables them to broaden their product portfolio and address new customer segments. Academic entrepreneurs only possess in-depth market knowledge when their venture targets other researchers as customers. These ventures may then be less risky but also more limited in their growth potential. We expect that they account for only a minority of all KIE firms started by academic entrepreneurs and hypothesize:

Hypothesis 3a: Having a founder with previous academic experience will not systematically increase the likelihood of survival of KIE firms.

Hypothesis $3 \mathrm{~b}$ : Having a founder with previous academic experience will lead to higher growth rates in a surviving KIE firm, but to a lesser extent than industry experience.

Summing up these hypotheses, we predict that only entrepreneurial experience has a systematic positive association with survival of KIE firms. No systematic positive association is expected from either industry or academic experience. Regarding growth, we expect industry experience to have a stronger positive statistical association than academic experience, while no systematic association is expected between entrepreneurial experience and firm growth. 


\subsection{Multiple types of experience}

Drawing on the KIE literature, we have indications about the relationship between more different types and combinations of founder experience within a venture and the effect this could have on opportunity recognition and performance of the firm. McKelvey and Lassen (2013) argue that KIE firms that draw on diverse types of relevant knowledge, including business, market, and scientific/technological knowledge, will have better performance. These predictions are closely related to our experience types: entrepreneurial, industry, and academic, respectively. McKelvey and Lassen (2013) and later McKelvey (2016) and Malerba and McKelvey (2018a) also link these knowledge types to increased awareness of and ability to recognize different types of opportunities, from entrepreneurial opportunities according to the Austrian school of entrepreneurship (Hayak 1945; Kirzner 1973), scientific and technological opportunities in a Schumpeterian sense, and productive opportunities stemming from the resource-based view of the firm (Penrose 1959).

Beyond the KIE literature, we can also find parallel assertions in the NTBF literature: as it has been argued that new technology-based firms are dependent on the integration of scientific/technological knowledge as a core resource with skills and capabilities regarding understanding a market and running a business (Colombo and Grilli 2005; Zahra et al. 2007; Visintin and Pittino 2014). Considering this, we predict the following:

Hypothesis 4a: Having multiple types of founder experience present in the firm will systematically increase the likelihood of survival of KIE firms.

Hypothesis 4b: Having multiple types of founder experience present in the firm will lead to higher growth rates in a surviving KIE firm.

\section{Method}

\subsection{Data and sample}

Our empirical strategy enables us to capture a time dimension between founder work experience and KIE firm performance. We capture data to measure survival and performance in 2015 at the firm-level, and link it to data from 2011 about the characteristics of founders and firms, as developed in a large-scale European survey of knowledge-intensive entrepreneurial firms (AEGIS Project 2013).

The AEGIS survey is our starting point, as it was an exploratory attempt to map the activity and characteristics of knowledge-intensive entrepreneurship in Europe. The survey was designed by the research teams in the AEGIS project, and implemented through telephone interviews subcontracted to Global Data Collection Company. The survey drew largely from the Amadeus database, with supplementation from a few other databases. Amadeus is a massive firm database owned by Bureau van Dijk, a privately owned business intelligence conglomerate, covering over 12 million European-based business entities.

Originally the sectoral query used in identifying the sampling frame, which was targeted to maximize the frequency of KIE firms, returned 547,678 companies. After cleaning, this number dropped to 338,725 firms. $^{3}$ Contact information was found for 180,215 firms, and in

\footnotetext{
${ }^{3}$ For more extensive descriptive statistics, we refer the reader to Malerba et al. (2016).
} 
order to retrieve the target sample from each country and each sectoral grouping the dataset was complemented by a few other databases (Dun \& Bradstreet, Kompass, and others). This resulted in a final sampling frame of 202,286 firms. A target response rate was set at 4000 firms, and the sample was randomized with stratified sampling occurring in each distinct country (Croatia, Czech Republic, Denmark, France, Germany, Greece, Italy, Portugal, Sweden, and the United Kingdom). At survey completion, 4004 firms had been surveyed. The KIE definitions employed in the EU project (as later described in Malerba et al. 2016) served as a screening mechanism for the survey, where the firms needed to be: at the time less than 8 years of age; involved in market activities (exploiting innovative opportunities), as well as independent (e.g. no subsidiaries, just changed their legal status, etc). A number of questions related to knowledge, innovative, opportunities, and barriers. The survey was aimed to find KIE firms across sectors, where Table 1 shows the NACE classifications. Regarding the choice of certain low and medium tech sectors, a pilot project to AEGIS identified a subset of sectors in Europe that were crucial for growth in the region/nation, and for employment (EC 2006), in addition to containing high degrees of entrepreneurial activity in the countries sampled. Regarding service sectors, KIBS classifications from the OECD were applied, as well as other knowledge-rich service sectors at the NACE level (OBS in the data). So empirically, the firms sampled contain the often sampled NTBF-heavy sectors like pharmaceuticals, medical devices, and machinery, but also sectors that fall outside these to include more types of knowledge intensity and innovation. In other words, the AEGIS survey aimed at exploring the broader population of KIE firms by surveying diverse domains with high potential for KIE (Malerba et al. 2016). These include high tech sectors, where small, new firms are often innovators; low and medium tech sectors, where users and appliers of new scientific, technological and creative knowledge may be more prevalent; and finally knowledge-intensive service sectors, where more types of co-creation driven innovation and innovative applications of new knowledge (Tether 2000) are known to occur. ${ }^{4}$ In addition, micro firms (firms with 10 employees or less) constitute the majority of the firms sampled in the AEGIS survey (64\%), a population that receives as of yet little empirical attention in other large scale surveys. The survey included questions about the founder and founder team, and is ambitious in its depth of analysis of core constructs to isolate the knowledge-intensive and innovative components of the KIE venture. Many items in the AEGIS survey draw upon questions from validated existing surveys, such as the GEM and Community Innovation Survey (CIS) as well as new questions.

A limitation of the original AEGIS survey is that it does not include data about performance, nor allow longitudinal or hierarchical modeling potential, due to its crosssectional nature. Prior analysis based upon data from this survey either gives a broad overview of the characteristics of these firms (Malerba et al. 2016; Protogerou et al. 2017) or defines specific characteristics of KIE firms as compared to non (less) KIE firms (Malerba and McKelvey 2018a). To analyze performance in terms of both survival and growth rates, we have supplemented the original survey with data from the same Amadeus database from which the firms were originally drawn, which in the time since the survey was administered was merged into the larger Orbis database. This

\footnotetext{
${ }^{4}$ While not commonly sampled together, we include both low tech manufacturing and services in our sample in alignment with the conceptualization of knowledge intensive entrepreneurship, in which it is argues that innovative opportunities can be exploited in these sectors as well, in addition to the commonly researched high tech and medium tech manufacturing sectors. See Malerba et al. (2016) and Lassen et al. (2018) for further details.
} 
Table 1 Sectors included in the sample

A. High-technology manufacturing sectors

Aerospace

Computers and office machinery

Radio-television and communication equipment

Manufacture of medical, precision \& optical instruments (Scientific instruments)

Pharmaceuticals

B. Medium to high technology manufacturing sectors

Manufacture of electrical machinery \& apparatus

Manufacture of machinery and equipment

Chemical industry (excluding pharmaceuticals)

C. Low to medium technology manufacturing sectors

Wood and furniture

Basic metals

Fabricated metal products

D. Low technology manufacturing sectors

Paper and printing

Textiles and clothing

Food, beverages and tobacco

E. Knowledge intensive business service (KIBS) sectors

Telecommunications

Computer and related activities

Research and experimental development

F. Other business service sectors

Legal/accounting; technical consulting including architectural and engineering activities; technical testing and analysis; labor recruitment and personnel provisioning; other miscellaneous business activities

Sectoral composition of sample

$\begin{array}{lllll} & \text { HTMS (A + B) } & \text { LTMS (C + D) } & \text { KIBS (E) } & \text { OBS (F) } \\ \text { AEGIS sample } & 10.5 \% & 40.0 \% & 15.3 \% & 34.2 \% \\ \text { Survival sample } & 8.2 \% & 28.6 \% & 19.5 \% & 43.7 \% \\ \text { Quantile sample } & 8.7 \% & 26.9 \% & 19.1 \% & 45.3 \%\end{array}$

was possible for 2978 of the 4004 firms in the AEGIS sample. Due to the matching of these two datasets, as well as further complications of missing values in the data, the sample size in the growth and survival regressions was considerably reduced. However, descriptive statistics below show that the variables do not drastically change in value, and our sample size is still adequate for the type of modelling used, and through testing for the characteristics of the missing data (which we assess as being missing at random (MAR)) we are confident that the models are not compromised by the missingness in the data (see Tables 2, 3, 4, 5, and 6 for details). ${ }^{5}$

\footnotetext{
${ }^{5}$ More details are available in Gifford (2017) regarding the missingness and imputation tests done on this combined unique data set.
} 
Table 2 Description of response variables

\begin{tabular}{llllllllllr}
\hline Industry & Mean & SD & Q0 & Q25 & Q50 & Q75 & Q100 & N & Missing \\
\hline 1 & Firm exit (hazard ratio) & 0.17 & 0.38 & & & & & & 2855 & 123 \\
2 & Average employment growth & 0.04 & 0.20 & -0.82 & 0.00 & 0.00 & 0.09 & 2.5 & 1098 & 1263 \\
3 & Average operating revenue growth & 1.44 & 54.36 & -0.63 & -0.01 & 0.00 & 0.02 & 2154.74 & 1571 & 790 \\
\hline
\end{tabular}

\subsection{Measures}

Dependent variables Firm exit, or, the Cox proportional hazard function of whether or not the firm was marked as inactive during the period between founding and the present date was derived. ${ }^{6}$ This model is often applied to studying the exit by entrepreneurial ventures (Agarwal and Audretsch 2001; Esteve-Peréz and Mañez-Castillejo 2008; Segarra and Callejón 2002; Strotmann 2007). The Cox model is useful in research problems where the baseline hazard function is unknown or otherwise hard to estimate, as is often the case with firm-level survival data. This is because the Cox model leaves the baseline hazard function unspecified, taking on a semi-parametric character. The flexibility of the Cox function also makes it ideal for application in our hybrid crosssectional dataset drawing from Orbis data as the AEGIS survey, since this data is a combination of two dataset largely containing time invariant independent variables. To combat potential survival bias in the data, left truncation to the model was applied by specifying the time in the firms' lifespan which the surveying took place.

To derive survival information from the data, the firms in the AEGIS survey was combined with the firm status variables used in Orbis, and matched by ID number. Accordingly, the survival analysis dataset is limited to those 2978 firms in the AEGIS survey that were taken from Amadeus/Orbis. Since the survival indicator was collected via Orbis at a later date (October, 2015) than the administration of the survey (ranging from the fall of 2010 to the spring of 2011), it serves as a valid indicator.

Firm growth The firm growth analysis is based upon the same 2978 firms, by using this additional financial reporting data. Specifically, we calculate the averaged year-on-year natural logarithmic growth of number of employees and logarithmic operating revenue growth of the firm over 6 years (2010-2015) (cf. Bracker et al. 1988; Coad et al. 2016; McKiernan and Morris 1994). Firm growth is a heterogeneous concept that is best measured using multiple indicators (Delmar et al. 2003; Coad et al. 2016; Haltiwanger et al. 2013).

In addition, we use a quantile regression approach for growth. By viewing Figs. 1 and 2, the quantile comparison plots of the two growth variables, and Figs. 3 and 4, the corresponding density plots, it is apparent that many firms in the sample have not experienced any growth at all., but also that something interesting is occurring in the tails of the distribution. A quantile regression approach, since the technique is extremely resilient to skewed data, and helps us assess statistical associations with different 'centers of gravity' in the data space.

\footnotetext{
${ }^{6}$ For more details about the shaping of the survival indicators of this particular data, cf. Gifford (2017: 167). Very few firms from the sample were marked as dissolved due to merger or acquisition (only 6) and so these firms were simply not included in the analysis.
} 
Table 3 Description of explanatory variables

\begin{tabular}{|c|c|c|c|c|c|c|}
\hline & Variable & Mean & SD & Median & $\mathrm{N}$ & Missing \\
\hline \multicolumn{7}{|c|}{ AEGIS survey only } \\
\hline 1 & Entrepreneurship experience & 0.33 & 0.47 & 0.00 & 3947 & 57 \\
\hline 2 & Industrial experience & 0.50 & 0.50 & 1.00 & 3947 & 57 \\
\hline 3 & Academic experience & 0.03 & 0.16 & 0.00 & 3947 & 57 \\
\hline 4 & Total experience & 0.86 & 0.54 & 1.00 & 3947 & 57 \\
\hline 5 & Knowledge intensive employees & 0.41 & 0.49 & 0.00 & 2839 & 139 \\
\hline 6 & Super knowledge intensity & 0.34 & 0.46 & 0.00 & 3900 & 104 \\
\hline 7 & International sales & 0.14 & 0.26 & 0.00 & 4004 & 0 \\
\hline 8 & Competitive barriers & 0.00 & 1.47 & 0.02 & 4004 & 0 \\
\hline 9 & Crisis & 0.00 & 1.71 & 0.67 & 3191 & 813 \\
\hline 10 & Firm age & 11.11 & 2.17 & 11.00 & 4004 & 0 \\
\hline 11 & Past employee growth (\%) & 19.77 & 73.24 & 0.00 & 3697 & 307 \\
\hline 12 & Past sales growth $(\%)$ & 28.21 & 131.02 & 10.00 & 3662 & 342 \\
\hline 13 & Regulatory barriers & 0.00 & 2.04 & -0.10 & 4004 & 0 \\
\hline 14 & $\mathrm{R} \& \mathrm{D}$ intensity & 0.12 & 0.19 & 5.00 & 4004 & 0 \\
\hline 15 & Team size & 2.20 & 1.43 & 2.00 & 3947 & 57 \\
\hline \multicolumn{7}{|c|}{ Hazard sample (AEGIS + Orbis) } \\
\hline 1 & Entrepreneurship experience & 0.32 & 0.47 & 0.00 & 2938 & 40 \\
\hline 2 & Industrial experience & 0.51 & 0.50 & 1.00 & 2938 & 40 \\
\hline 3 & Academic experience & 0.03 & 0.17 & 0.00 & 2938 & 40 \\
\hline 4 & Total experience & 0.85 & 0.54 & 1.00 & 2938 & 40 \\
\hline 5 & Knowledge intensive employees & 0.41 & 0.49 & 0.00 & 2839 & 139 \\
\hline 6 & Super knowledge intensity & 0.34 & 0.47 & 0.00 & 2901 & 77 \\
\hline 7 & International sales & 0.14 & 0.26 & 0.00 & 2978 & 0 \\
\hline 8 & Competitive barriers & 0.00 & 1.47 & 0.02 & 2978 & 0 \\
\hline 9 & Crisis & 0.00 & 1.71 & 0.67 & 2367 & 611 \\
\hline 10 & Firm age & 10.67 & 2.31 & 10.00 & 2811 & 167 \\
\hline 11 & Past employee growth & 20.74 & 75.78 & 0.00 & 2806 & 172 \\
\hline 12 & Past sales growth & 31.80 & 146.19 & 15.00 & 2783 & 195 \\
\hline 13 & Regulatory barriers & 0.00 & 2.04 & -0.10 & 2978 & 0 \\
\hline 14 & $\mathrm{R} \& \mathrm{D}$ intensity & 0.13 & 0.20 & 5.00 & 2978 & 0 \\
\hline 15 & Team size & 2.20 & 1.43 & 2.00 & 2938 & 40 \\
\hline \multicolumn{7}{|c|}{ Conditional quantile sample (AEGIS + Orbis) } \\
\hline 1 & Entrepreneurship experience & 0.32 & 0.47 & 0.00 & 2325 & 36 \\
\hline 2 & Industrial experience & 0.51 & 0.50 & 1.00 & 2325 & 36 \\
\hline 3 & Academic experience & 0.03 & 0.16 & 0.00 & 2325 & 36 \\
\hline 4 & Total experience & 0.86 & 0.53 & 1.00 & 2325 & 36 \\
\hline 5 & Knowledge intensive employees & 0.43 & 0.50 & 0.00 & 2247 & 114 \\
\hline 6 & Super knowledge intensity & 0.34 & 0.48 & 0.00 & 2299 & 62 \\
\hline 7 & International sales & 0.14 & 0.27 & 0.00 & 2361 & 0 \\
\hline 8 & Competitive barriers & 0.00 & 1.48 & 0.02 & 2361 & 0 \\
\hline 9 & Crisis & 0.00 & 1.69 & -0.58 & 1870 & 491 \\
\hline
\end{tabular}


Table 3 (continued)

\begin{tabular}{lllllll}
\hline & Variable & Mean & SD & Median & N & Missing \\
\hline 10 & Firm age & 10.90 & 2.17 & 10.00 & 2361 & 0 \\
11 & Past employee growth & 21.00 & 71.30 & 0.00 & 2227 & 134 \\
12 & Past sales growth & 33.31 & 157.23 & 15.00 & 2209 & 152 \\
13 & Regulatory barriers & 0.00 & 2.04 & -0.09 & 2361 & 0 \\
14 & R\&D intensity & 0.13 & 19.70 & 5.00 & 2361 & 0 \\
15 & Team size & 2.24 & 1.45 & 2.00 & 2325 & 36 \\
\hline
\end{tabular}

Table 4 Principal Component inter-correlations

Rating scale question:

Could you please indicate the impact (if any) of the current economic crisis on your firm in Crisis terms of the following elements (please consider the effect on the activity of 2009 compared to the activity of 2008)

Sales

Exports

Employment

Profits

Investments

Rating scale question:

Please indicate how serious the following barriers have been to the firm growth and expansion of business activities. On a 5 point scale, where 1 is no barriers and 5 is very serious barriers.

Continuously changing taxation regulations

High tax rates

Regulatory barriers

Time consuming regulatory requirements for issuing permits and licenses

Poorly enforced competition law to curb monopolistic practices

0.70

Poorly enforced property rights, copyright and patent protection

Strict property, copyright and patent protection

Government officials favor well connected individuals

Bankruptcy legislation makes the cost of failure immense

Rigid labor market legislation

Rating scale question:

Please indicate to what extent the following factors have been obstacles to the firm growth and expansion of business activities. On a 5 point scale, where 1 is not at all and 5 is to a great extent:

Technological risk/uncertainty

Market risk/uncertainty

Difficulty in finding the necessary funding for growth investments

Difficulty in finding business partners

Difficulties in recruiting highly-skilled employees 
Table 5 Inter-correlations among measures: hazard sample

$\begin{array}{lllll}1 & 2 & 3 & 4 & 5\end{array}$

$1 \quad$ Knowledge intensive employees

2 Super knowledge intensity

\begin{tabular}{|c|c|c|c|c|}
\hline \multicolumn{5}{|l|}{$0.24 * * *$} \\
\hline $0.13 * * *$ & $0.12 * * *$ & & & \\
\hline$-0.08 * * *$ & 0.01 & $-0.05 * *$ & & \\
\hline 0.02 & -0.02 & $-0.09 * * *$ & $-0.39 * * *$ & \\
\hline$-0.05^{*}$ & $0.10^{* * *}$ & 0.01 & $0.06^{* *}$ & -0.01 \\
\hline$-0.15^{* * *}$ & -0.02 & $-0.04 *$ & $0.10 * * *$ & $-0.08^{* * * *}$ \\
\hline-0.02 & -0.02 & 0.04 & $0.04 *$ & 0.00 \\
\hline $0.08 * * *$ & $0.09 * * *$ & $0.12 * * *$ & -0.01 & $-0.04^{*}$ \\
\hline $0.08 * * *$ & $0.07 * * *$ & $0.06 * *$ & -0.02 & 0.02 \\
\hline $0.13 * * *$ & $0.13 * * *$ & $0.08 * * *$ & $0.05^{* *}$ & 0.01 \\
\hline $0.18 * * *$ & $0.23 * * *$ & $0.19 * * *$ & $0.06^{* *}$ & $-0.07 * * *$ \\
\hline $0.05 * *$ & $-0.16^{* * *}$ & $-0.07 * * *$ & -0.02 & -0.02 \\
\hline-0.03 & -0.01 & -0.01 & $0.12 * * *$ & -0.03 \\
\hline $0.07 * * *$ & 0.02 & 0.01 & 0.02 & 0.03 \\
\hline$-0.08 * * *$ & -0.01 & -0.01 & -0.01 & -0.03 \\
\hline$-0.04 *$ & $0.16^{* * *}$ & $0.09 * * *$ & $0.16^{* * *}$ & $0.07 * * *$ \\
\hline-0.02 & 0.03 & $0.18 * * *$ & $0.49 * * *$ & $0.56^{* * * *}$ \\
\hline 11 & 12 & 13 & 14 & 15 \\
\hline
\end{tabular}

3 Academic experience

ce

$4 \quad$ Entrepreneurial experience

5 Industrial experience

6 Competitive barriers

7 Regulatory barriers

8 Crisis

9 Past sales growth

10 Past employment growth

11 International sales

12 R\&D intensity

13 Sector

14 EU Region

15 Firm age

16 Firm exit

17 Team size

18 Total experience

Variables

0.03

11 International sales

$0.09 * * *$

$0.21 * * *$

13 Sector

14 EU Region

15 Firm age

16 Firm Exit

17 Team size

18 Total experience

$-0.03$

$-0.11^{* * *}$

$-0.16^{* * * *}$

$\begin{array}{llll}0.01 & 0.00 & 0.03 & 0.02\end{array}$

$-0.11^{* * * *}$

$0.06^{* *}$

0.02

0.00

$-0.02$

$0.01 \quad-0.03$

0.00

$-0.02$

0.00

0.01

$0.04^{*}$

$0.07 * * *$

$-0.06^{*}$

$0.08 * * *$

$0.08 * * *$

$0.05 *$

$-0.05 * *$

$0.08 * * *$

0.03

6

7
8

9
10
1

2

3

4

5

6

7

8

9

10

11

12

13

$\begin{array}{ll}0.47 * * * & \\ -0.15 * * * & -0.07 * * * \\ -0.03 & -0.03 \\ 0.03 & -0.01 \\ 0.06 * * & -0.04 * \\ 0.16 * * * & 0.02 \\ -0.15 * * * & -0.04 *\end{array}$

$0.16^{* * *}$
$0.20^{* * *}$
-0.01
0.01
0.00

$\begin{array}{ll}0.39 * * * & \\ 0.01 & 0.00 \\ 0.09 * * * & 0.08 * * * \\ -0.03 & -0.03\end{array}$


Table 5 (continued)

\begin{tabular}{llllll}
\hline 14 & $0.05^{* *}$ & $0.12^{* * *}$ & $0.08^{* * *}$ & -0.01 & -0.01 \\
15 & $0.05^{*}$ & $0.04^{*}$ & $-0.07^{* *}$ & $-0.08^{* * *}$ & $-0.08^{* * * *}$ \\
16 & $0.09^{* * *}$ & $0.06^{* *}$ & $-0.13^{* * *}$ & -0.02 & -0.02 \\
17 & 0.03 & -0.01 & 0.00 & 0.01 & 0.01 \\
18 & $0.04^{*}$ & -0.00 & $0.05^{*}$ & -0.01 & 0.02 \\
& 16 & 17 & & & \\
11 & & & & \\
12 & & & & \\
13 & & & & \\
14 & & & & \\
15 & & & & \\
16 & $-0.25^{* * *}$ & & & \\
17 & $0.11^{* * *}$ & $-0.04 *$ & & \\
18 & 0.02 & $0.23 * * *$ & & \\
\hline
\end{tabular}

$* p<.05$

$* * p<.01$

$* * * p<.001$

Therefore, in order to estimate the growth regressions appropriately, we chose to employ the quantile regression (inclusion of observations conditional on survival). Quantile regression is an alternative to mean regression (which has proven problematic in assessing firm growth outcomes due to inherent biases of firm size and growth, including growth outcomes for small and micro firms (Haltiwanger et al. 2013). Table 2 conveys the summarized descriptive statistics of all four outcome variables used in our models. When reporting our statistical results for the growth regressions, we follow previous research on firm growth (Coad et al. 2016) by making use of the $0.05,0.10,0.25,0.50,0.75,0.90$, and 0.95 quantiles. However, we view 'high growth' as the growth at or above the 90th quantile, so in the subsequent text we focus our results on the 90th and 95 th quantile.

Independent variables Entrepreneurial experience is a binary variable taking the value 1 if one or more of the founders had prior experience either owning an existing firm, owning a firm that has ceased operations, or was self-employed, and taking the value 0 otherwise. Academic experience is a binary variable taking the value 1 if one or more of the founders of the venture had prior work experience at a university or research institute, and 0 otherwise. This serves as a commonly applied proxy for the firm being an academic spinoff (Perkmann and Walsh 2007; Perkmann et al. 2013). Industry experience is a binary variable taking the value 1 if one or more of the founders of the venture had prior experience working in the same industry as the focal firm, and 0 otherwise. Lastly, Total experience is a categorical variable $(0-3)$ that sums all types of above experience present in the founder(s) of any given firm. 
Table 6 Inter-correlations among measures: conditional quantile sample

$\begin{array}{lllll}1 & 2 & 3 & 4 & 5\end{array}$

$1 \quad$ Knowledge intensive employees

2 Super knowledge intensity

\begin{tabular}{|c|c|c|c|c|}
\hline \\
\hline \multicolumn{5}{|l|}{$\begin{array}{l}0.25 * * * \\
0.12 * * *\end{array}$} \\
\hline$-0.09 * * *$ & 0.00 & $-0.05 * *$ & & \\
\hline 0.02 & -0.02 & $-0.10 * * *$ & $-0.40 * * *$ & \\
\hline-0.03 & $0.11 * * *$ & 0.00 & $0.5 *$ & -0.02 \\
\hline$-0.15^{* * *}$ & -0.03 & $-0.05^{*}$ & $0.11^{* * * *}$ & $-0.09 * * *$ \\
\hline 0.01 & 0.02 & -0.04 & $-0.5^{*}$ & 0.02 \\
\hline $0.08 * * *$ & $0.08 * * *$ & $0.14 * * *$ & -0.02 & $-0.05^{*}$ \\
\hline $0.10 * * *$ & $0.07 * * *$ & $0.07 * *$ & -0.03 & 0.01 \\
\hline $0.04 *$ & 0.02 & 0.01 & 0.01 & 0.03 \\
\hline $0.13 * * *$ & $0.13 * * *$ & $0.10 * * *$ & 0.04 & 0.01 \\
\hline $0.18 * * *$ & $0.24 * * *$ & $0.19 * * *$ & $0.05^{*}$ & $-0.07 * * *$ \\
\hline $0.04 *$ & $-0.17 * * *$ & $-0.06 * *$ & -0.01 & -0.02 \\
\hline-0.04 & -0.02 & -0.01 & $0.13^{* * *}$ & -0.04 \\
\hline-0.02 & 0.04 & $0.10 * * *$ & 0.01 & -0.02 \\
\hline-0.03 & 0.03 & 0.00 & -0.02 & -0.02 \\
\hline$-0.04 *$ & $0.16^{* * * *}$ & $0.06^{* * *}$ & $0.16^{* * *}$ & $0.08 * * *$ \\
\hline 0.01 & -0.00 & 0.19 & 0.49 & 0.51 \\
\hline 11 & 12 & 13 & 14 & 15 \\
\hline
\end{tabular}

3 Academic experience

4 Entrepreneurial experience

5 Industrial experience

6 Competitive barriers

7 Regulatory barriers

8 Crisis

9 Past sales growth

10 Past employment growth

11 Firm age

12 International sales

13 R\&D intensity

14 Sector

15 EU Region

16 Average employment growth

17 Average operating revenue growth

18 Team size

19 Total experience

Variables

y

(n)

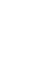


Table 6 (continued)

\begin{tabular}{|c|c|c|c|c|c|}
\hline 12 & $0.07 * * *$ & -0.02 & 0.03 & 0.00 & 0.04 \\
\hline 13 & $0.15 * * *$ & 0.03 & 0.00 & $0.09 * * *$ & $0.10 * * *$ \\
\hline 14 & $-0.15 * * *$ & -0.04 & -0.01 & $-0.04 *$ & -0.03 \\
\hline 15 & 0.05 & $0.11 * * *$ & $-0.11 * * *$ & -0.01 & 0.02 \\
\hline 16 & -0.01 & -0.03 & $-0.12 * * *$ & 0.05 & $0.07 *$ \\
\hline 17 & 0.01 & 0.00 & -0.02 & -0.01 & -0.01 \\
\hline 18 & 0.02 & $0.07 * * *$ & -0.02 & 0.03 & 0.01 \\
\hline \multirow[t]{2}{*}{19} & 0.04 & -0.00 & -0.05 & -0.03 & 0.01 \\
\hline & 16 & 17 & 18 & & \\
\hline \multicolumn{6}{|l|}{11} \\
\hline \multicolumn{6}{|l|}{12} \\
\hline \multicolumn{6}{|l|}{13} \\
\hline \multicolumn{6}{|l|}{14} \\
\hline \multicolumn{6}{|l|}{15} \\
\hline \multicolumn{6}{|l|}{16} \\
\hline 17 & $0.28 * * *$ & & & & \\
\hline 18 & $0.07 *$ & 0.01 & & & \\
\hline 19 & 0.04 & 0.04 & $0.22 * * *$ & & \\
\hline
\end{tabular}

$* p<.05$

$* * p<.01$

$* * * p<.001$

Controls We also include a set of control variables for all regression. To assess the association of the main explanatory variables on performance for KIE firms, we control for the richness of knowledge intensity in two ways. First, following Malerba and McKelvey's 'Super-KIE' coding method (Malerba and McKelvey 2018a), an entrepreneurial firm is coded as being 'Super knowledge intensive' in the following manner, if: i.) The firm has introduced an innovation in the past 3 years; ii.) At least one member of the founding team has completed at least a bachelor's degree; iii.) At least one member of the founding team has expressed their main area of competence to be technical and engineering knowledge, or, product design skills. This variable takes the value 1 if the firm satisfies all these prerequisites and 0 otherwise. We also address employee knowledge intensity using a binary variable denoting whether or not the firm has $33 \%$ or more of its employees possessing at least a tertiary degree (the European Commission $(2006,2013)$ defines industries with $33 \%$ tertiary education averages as knowledge intensive activities). Using this indicator, we control for knowledge intensity through non-founder human capital levels as previous studies have shown this aspect of human capital to also be influential for firm performance and growth (Delmar and Wennberg 2010; Siepel et al. 2017; Smith et al. 2005). This and the above variable both contain components of the education level of the founder as well as of the employees, so in a sense we control for this aspect of human capital investments (Becker 1964). Firm age: For growth regressions, we include a variable based on the year the venture was established subtracted from year of collecting data: 2015 (screened for change in legal status of existing firm). Team size: The size of the founding team, following 


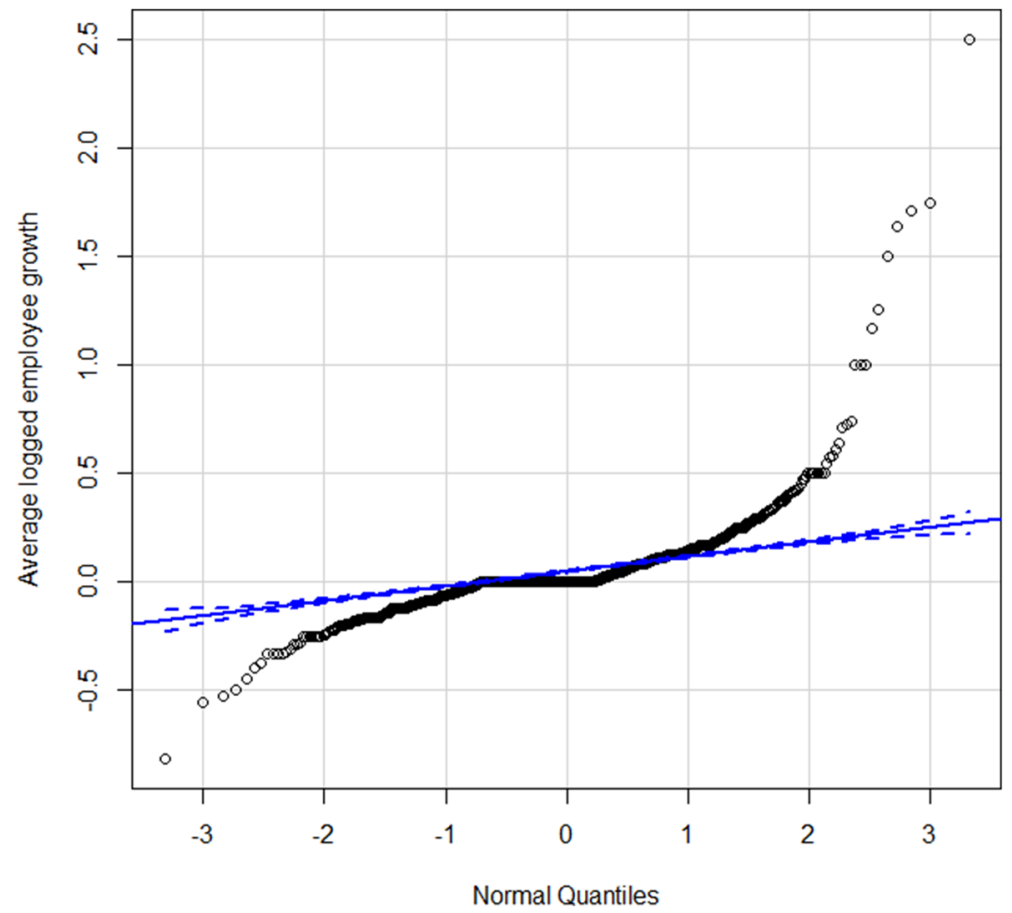

Fig. 1 Quantile and density plots of response variables of quantile regressions (top two observations trimmed for average operating revenue growth to smooth graphical proportions)

Agarwal and Audretsch (2001). International sales: Percentage of international sales estimated by survey respondents, was included due to previous research finding associations between early internationalization and knowledge intensity in new ventures concerning both growth (Autio et al. 2000), and survival (Sapienza et al. 2006; Mudambi and Zahra 2007). The logit, or log-odds, transformation was employed on this variable following graphical interpretation of the distribution of the data. $R \& D$ intensity: Self-estimated R\&D Intensity (by percentage of sales invested), in order to control for the effect of R\&D on our variables of interest (Hagedoorn and Cloodt 2003) and the effect of absorptive capacity of the firm (Cohen and Levinthal 1990; Tsai 2001). This variable is also transformed via a logit (log-odds) function.

We further control for the firm's industrial Sector: HTMS (High-tech and mediumto-high-tech manufacturing sectors), LTMS (Low and low-to-medium tech manufacturing sectors); KIBS (Knowledge intensive business services); OBS (Other business services). See Table 1 for sectors included as well as sectoral composition of the data used. Similar to the country identifiers, the sectors were derived from combining categorically the different sampled sectors. This was done to smooth out the effects of the control variable, and to match the categories assigned to the sectors in the AEGIS project and survey.

To control for the firm's degree of resilience during the economic crisis of 20082009 , a principal components analysis of the rating scale question estimating the degree of fluctuation (in percentile categories) of sales, exports, employment, profits and investments. The most influential component was extracted as a variable to control 


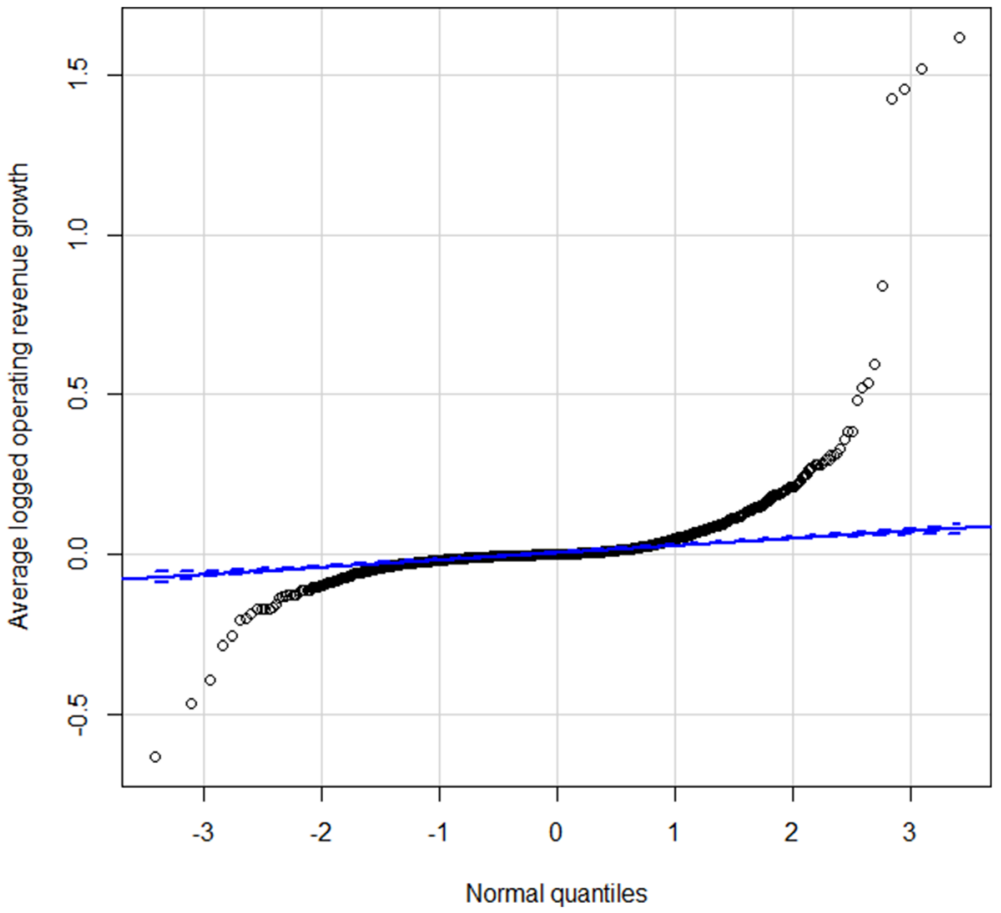

Fig. 2 Quantile and density plots of response variables of quantile regressions (top two observations trimmed for average operating revenue growth to smooth graphical proportions)

for the effects of the crisis, and is labeled Crisis. ${ }^{7}$ Self-reported past estimated fluctuation in sales (Past sales growth) as well as employees (Past employee growth) from 2007 to 2009 were also included as controls.

Lastly, we control for different types of growth barriers experienced by the firm. To this end two additional principal components analyses were conducted, respectively, on summated rating scales assessing competitive barriers to growth (including technology and market risk/uncertainties, initial investments, funding, partnerships, hiring, and technological know-how), and regulatory barriers to growth (including tax regulations and rates, time consuming bureaucracies, poorly enforced laws and IPR regulations, government favor, bankruptcy and insolvency proceedings, and labor market legislation). For each of these types of barriers, we selected the most influential component and added it as a control variable: Competitive barriers and Regulatory barriers, respectively. ${ }^{8}$

Table 3 shows the summary descriptive statistics of the explanatory and control variables in a manner similar to the response variables, both for the quantile and the Cox proportional hazard model samples. This is to show the comparability of the samples despite the change in number of observations. Table 4 shows the intercorrelations of the principal components used as control variables with their respective

\footnotetext{
${ }^{7}$ The Crisis variable explains 0.57 of the variance of the rating scale, with an eigenvalue of 2.86 .

${ }^{8}$ The component chosen for Competitive barriers yielded an explained variance of 0.37 , and an eigenvalue of 2.19, while the component for Regulatory barriers yielded an explained variance of 0.46 and an eigenvalue of 4.16. Table 8 shows all inter-correlations of the principal components.
} 


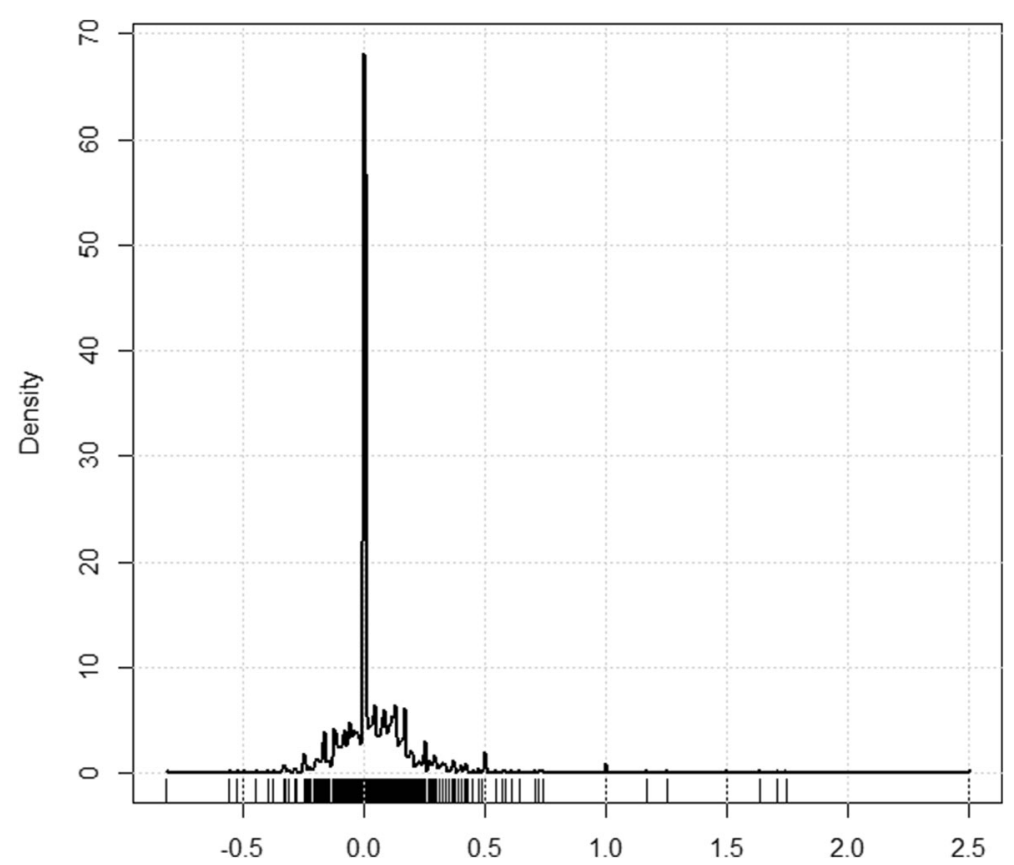

Fig. 3 Density estimate of dependent variable average logged employee growth

summative rating scales, while Tables 5 and 6 show inter-correlations between the variables in both sub-samples.

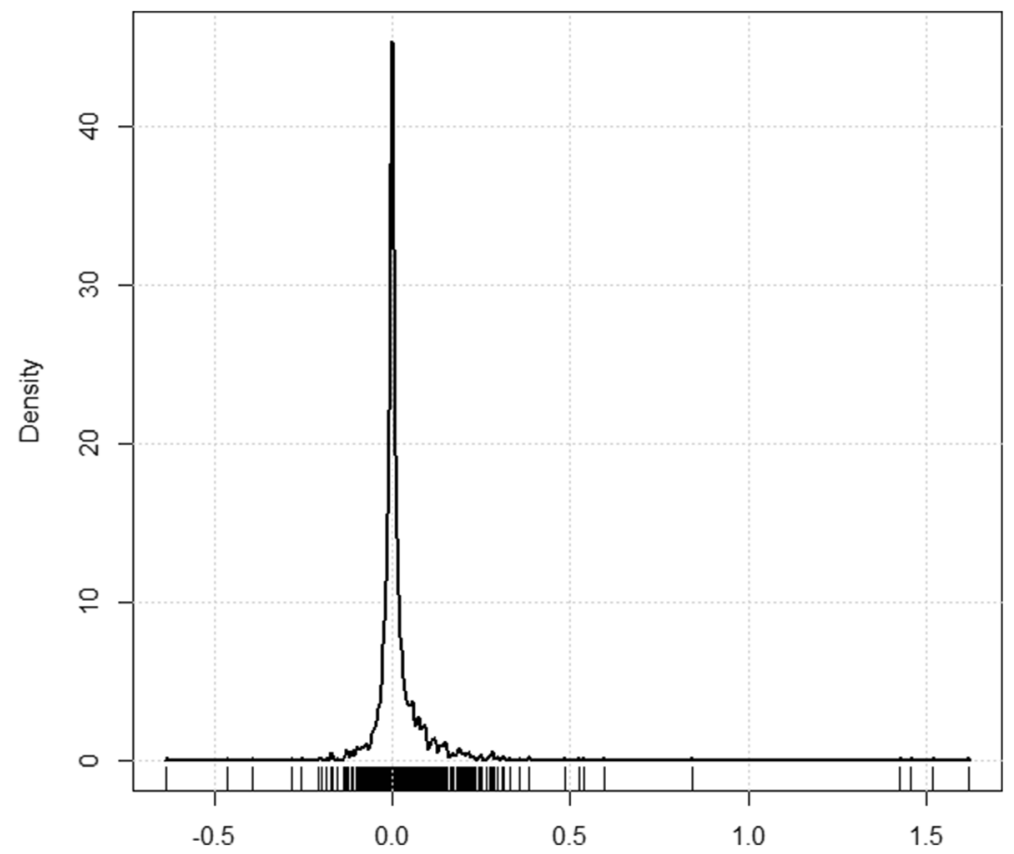

Fig. 4 Density estimate of dependent variable average logged operating revenue growth 


\section{Results}

Table 7 shows the results of the Cox PH models, with stepwise inclusion of the main explanatory variables, as well as the additional model with total experience as a categorical variable. In our quantile regression analysis, as previously stated, we focus on the top two reported quantiles, 0.90 and 0.95 , as a proxy for firms experiencing 'high growth', and flexibly interpret our findings for these two quantiles. However, in the Operating Revenue response variable model for total experience, we include the 0.98 quantile, as following graphical interpretation of the data, it was seen to contain additional effects not captured by the 0.95 quantile. We base our interpretation on the results in these areas of the data space for each response variable. Tables 8 and 9 show the results of the first quantile regression model with average employee growth as the response variable. The coefficients convey the marginal effects of the explanatory variables at the different quantiles. The operating revenue growth quantile regressions can be seen in Tables 10 and 11. Table 12 summarizes our results.

First, we turn to entrepreneurial experience of the founders and its relationship to survival and high growth of KIE firms. In the fully specified hazard model (Table 7), entrepreneurial experience decreases the likelihood of firm exit, and the effects are considerably more significant and greater in size when industrial experience appears in the same model. This confirms Hypothesis 1a.

Tables 8 and 9 shows that at the two highest reported quantiles, 0.90 and 0.95 , of average employee growth, entrepreneurial experience is statistically significant and positively related with marginal effects of 0.07 and 0.11 respectively. Concerning average operating revenue growth (Tables 10 and 11), entrepreneurial experience is statistically significant (at the $p<0.10$ level) and positive at the 0.95 quantile with a marginal effect of 0.01 . Thus, we interpret that entrepreneurial experience is positively associated with the upper quantile of both growth indicators, against our expectations in hypothesis $1 \mathrm{~b}$. Additionally, entrepreneurial experience seems to have more influence in predicting employee growth than operating revenue growth.

Moving on to industry experience: Industrial experience decreases likelihood of firm exit (Table 7), resulting in non-confirmation of hypothesis 2a. Again, a more sizable and more significant coefficient is obtained when included together with entrepreneurial experience. Industrial experience is statistically significant and positive $(p<0.05)$ at the 0.95 quantile of employee growth with a marginal effect of 0.06 (Tables 8 and 9), but is negatively associated with average revenue growth at the $0.90(p<.05)$ and 0.95 $(p<0.001)$ quantiles with marginal effects of -0.02 for both (Tables 10 and 11). Given these inconsistent findings, we reject hypothesis $2 b$.

For academic experience: As shown in Table 7, academic experience is not significantly associated with firm exit likelihood in any specification, supporting hypothesis 3a. Note, however, that only $3 \%$ of the sample reported a founder with academic experience, resulting in relatively imprecise coefficient estimates. In contrast, when analyzing high growth, academic experience is statistically significant and positive at the quantiles $0.90(p<0.01)$ and $0.95(p<0.001)$ of average employee growth with marginal effects of 0.20 and 0.24 , respectively (Tables 8 and 9 ). These are by far the largest estimates of any independent variables on employee growth. Moreover, academic experience is statistically significant and positive $(p<0.001)$ at the 0.95 quantile of operating revenue growth with a still relatively large marginal effect of 0.13 (Tables 10 


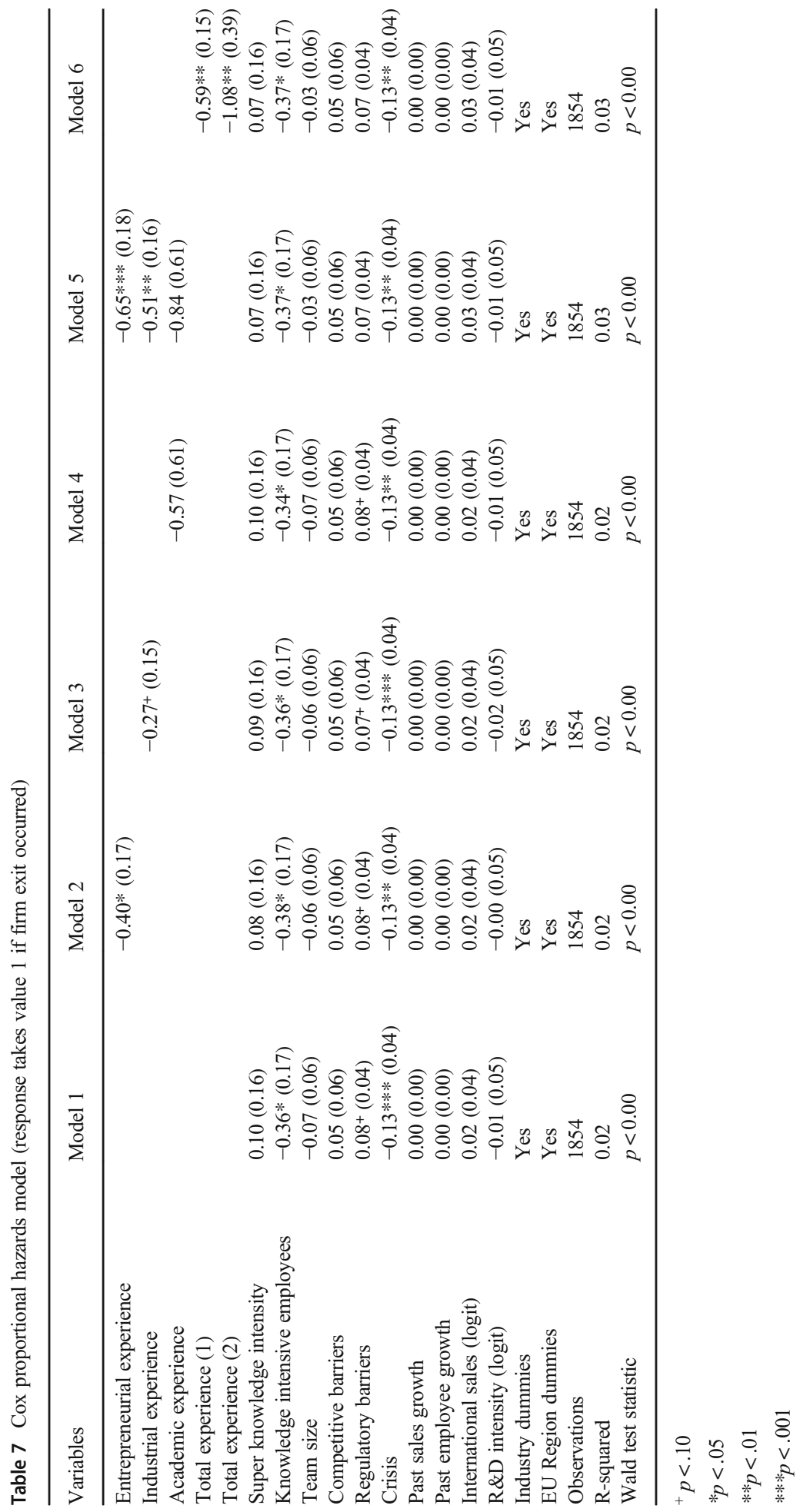




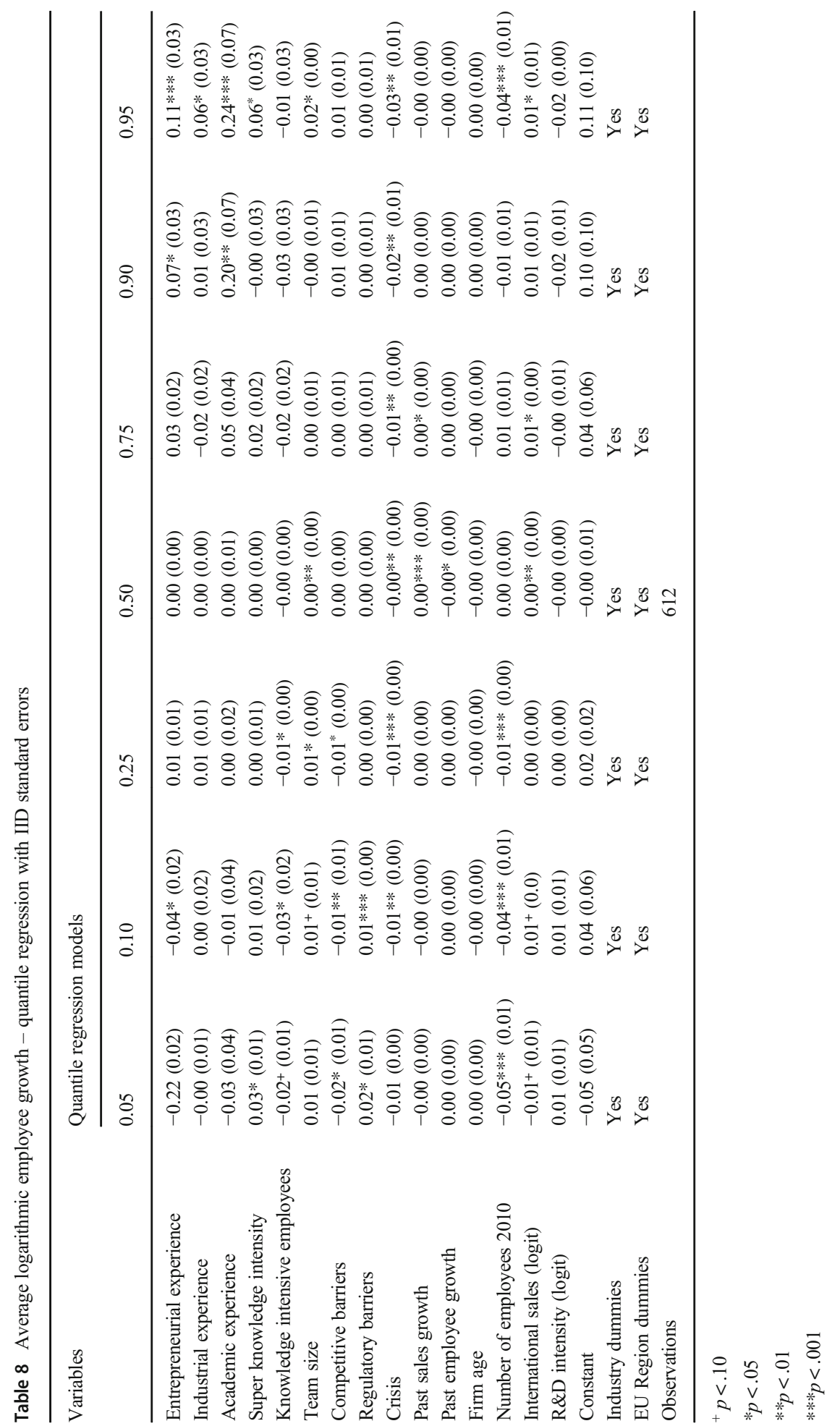




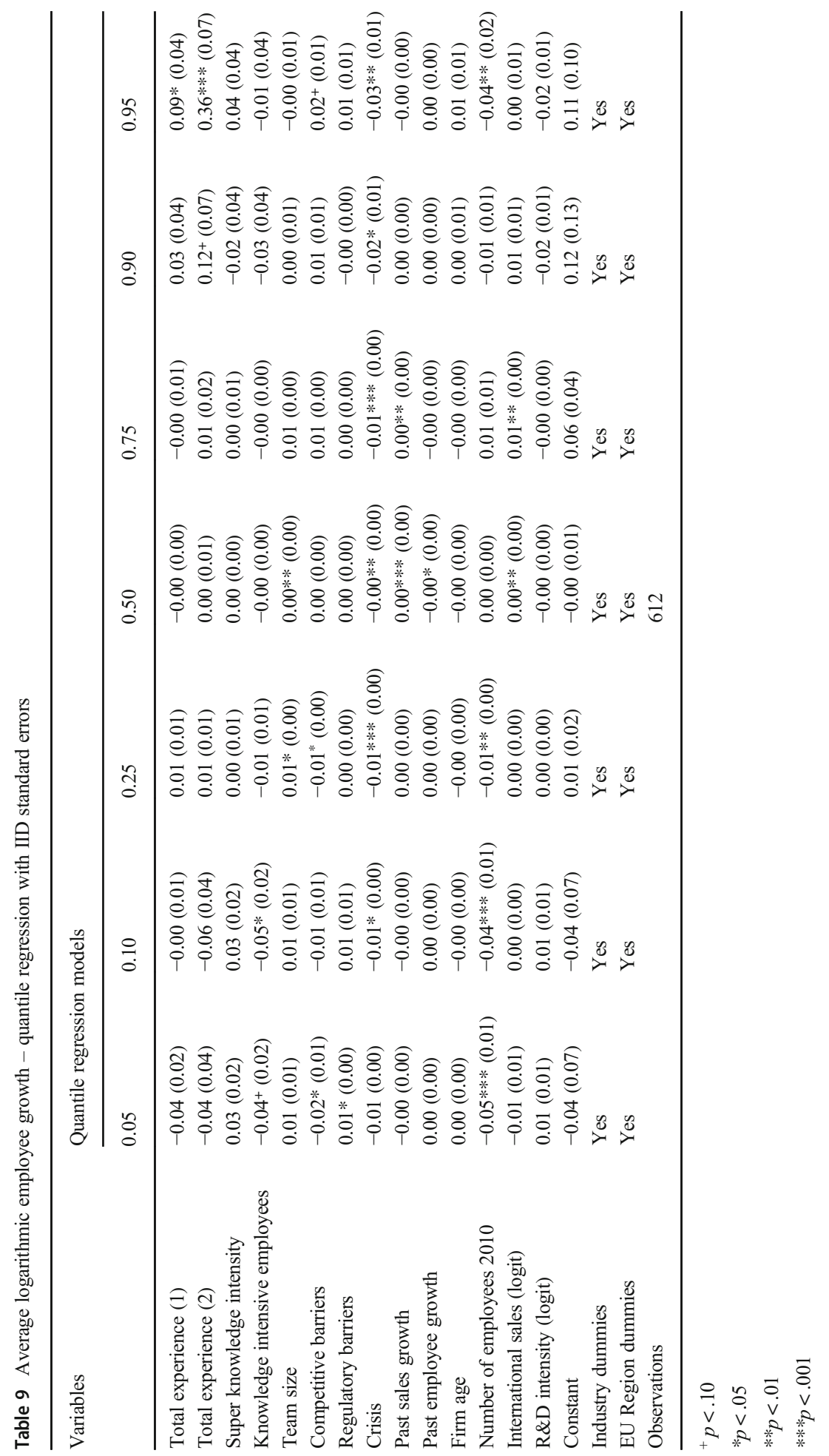




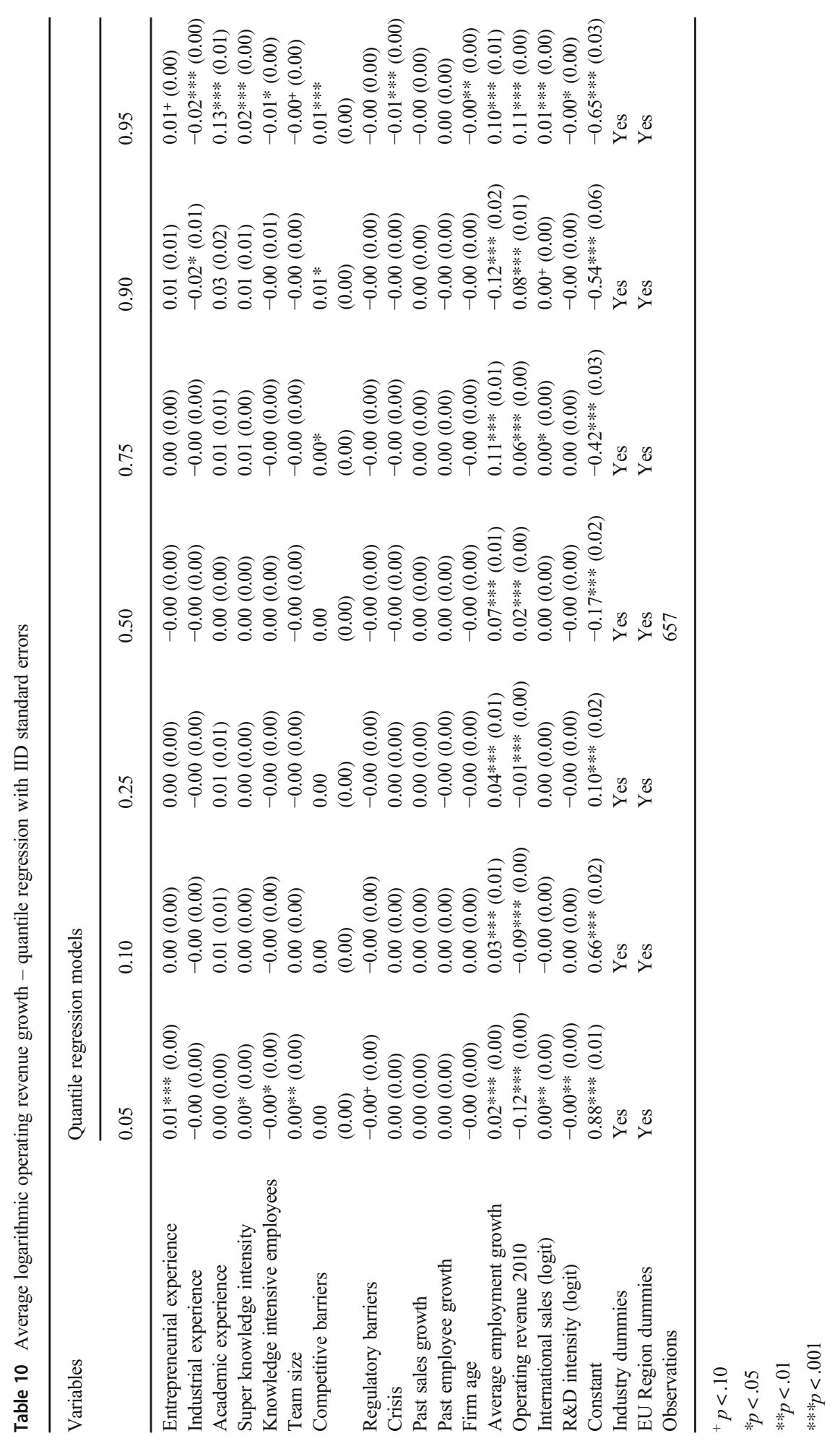




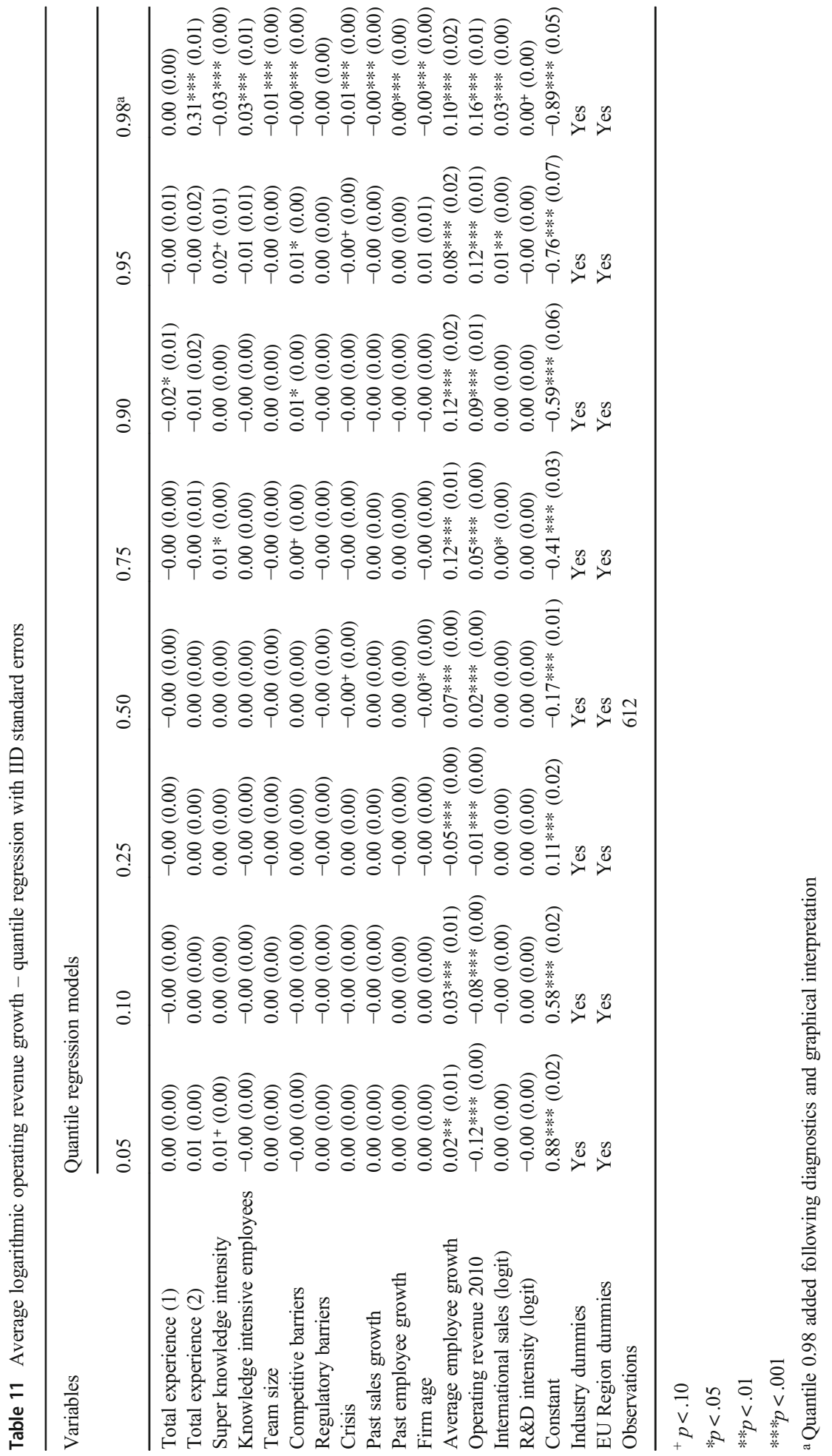




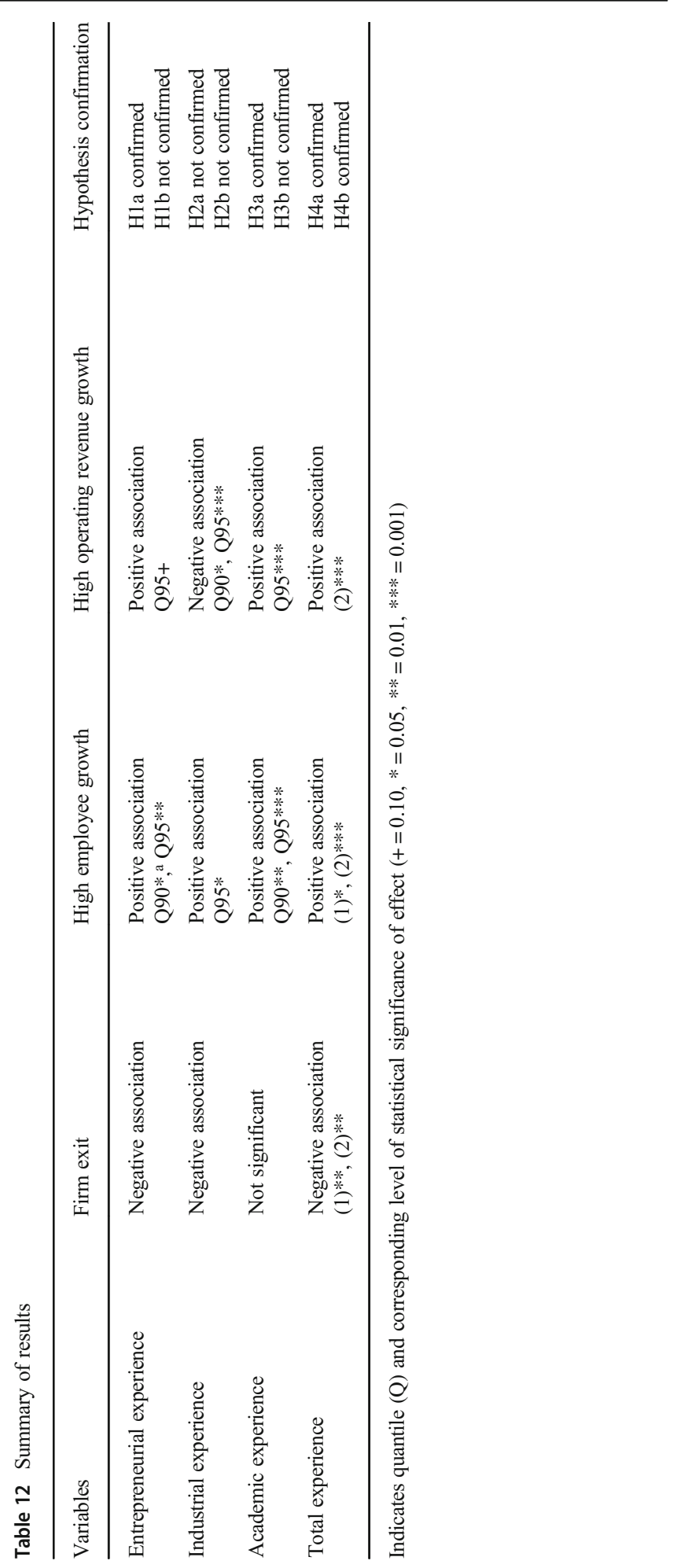


and 11). These patterns provide partial support to hypothesis $3 \mathrm{~b}$, as academic experience is strongly positively associated with the upper quantiles of both growth indicators, but it also has a stronger effect than industry experience in both growth regressions.

Concerning the total amount of the three types of experience in a firm, we find that for survival, a firm benefits both from having one type of experience rather than none at all, as well as having two types of experience on the team, meaning that the more combined types of the three experience, the higher the likelihood of survival. It should be noted however that no firm in the sample seems to have all three types of experience in their founding team according to the survey. Concerning firm growth, we find similar results for employee growth, with significant effects at both one and two types of experience as opposed to none. However, for operating revenue, when looking at the 0.98 quantile we find that there is a strongly statistically significant effect of having a combination of two types of experience rather than none, whereas one type rather than none is not significant. In both cases, the more types of founder experience (university, industry and/or entrepreneurial) present in the firm, the better the overall performance in terms of both survival and at high growth quantiles.

Concerning our knowledge intensity related controls: For high growth firms, their growth positively associates with being a 'super' KIE firm for both employee growth $(p<0.05)$ and operating revenue $(p<0.001)$ at the 0.95 quantile. Having knowledge intensive employees also reduces the likelihood of firm exit, and associates negatively with operating revenue growth at the 0.95 quantile.

Figures 5 and 6 convey the graphical representations of the quantile regression results for each of the main independent and dependent variables. Here can be seen sharply increasing coefficient values at the upper tails of both entrepreneurial and academic experience, as well as total experience, denoting a striking performance difference in relative to the rest of the growth distributions.

\section{Robustness checks}

In order to obtain more precise estimations, we tried several different sets of specifications that excluded certain control variables that added a large amount of missingness to the regression (Crisis, Past Sales, Past Employment, Competitive Barriers, and Regulatory Barriers). Performing the regressions without these variables did not seem to overall impact the sign or significance levels of the explanatory variables. To check the high growth outcomes ${ }^{9}$ of the firms in another way, we also ran binary logit models for each growth response variable where the value of 1 was assigned for firms above the 0.90 quantile as well as additional models for firms above the 0.95 quantile. For average employee growth above the 0.95 quantile, the positive association with academic experience was the only explanatory variable that showed statistical significance in the fully specified model. For operating revenue growth, the association with industrial experience was negative $(p<.05)$ above the 0.90 quantile, otherwise nothing

\footnotetext{
${ }_{9}$ Additionally, we ran separate quantile regressions for productivity growth, which we operationalized as the quotient of operating revenue and employee growth, the latter being the denominator. This is also an oftenused growth indicator for small firms (cf. McKiernan and Morris 1994). We obtained the hypothesized results, with the exception of industrial experience, which was not found to be significant, but retained the same sign as the operating revenue effect.
} 

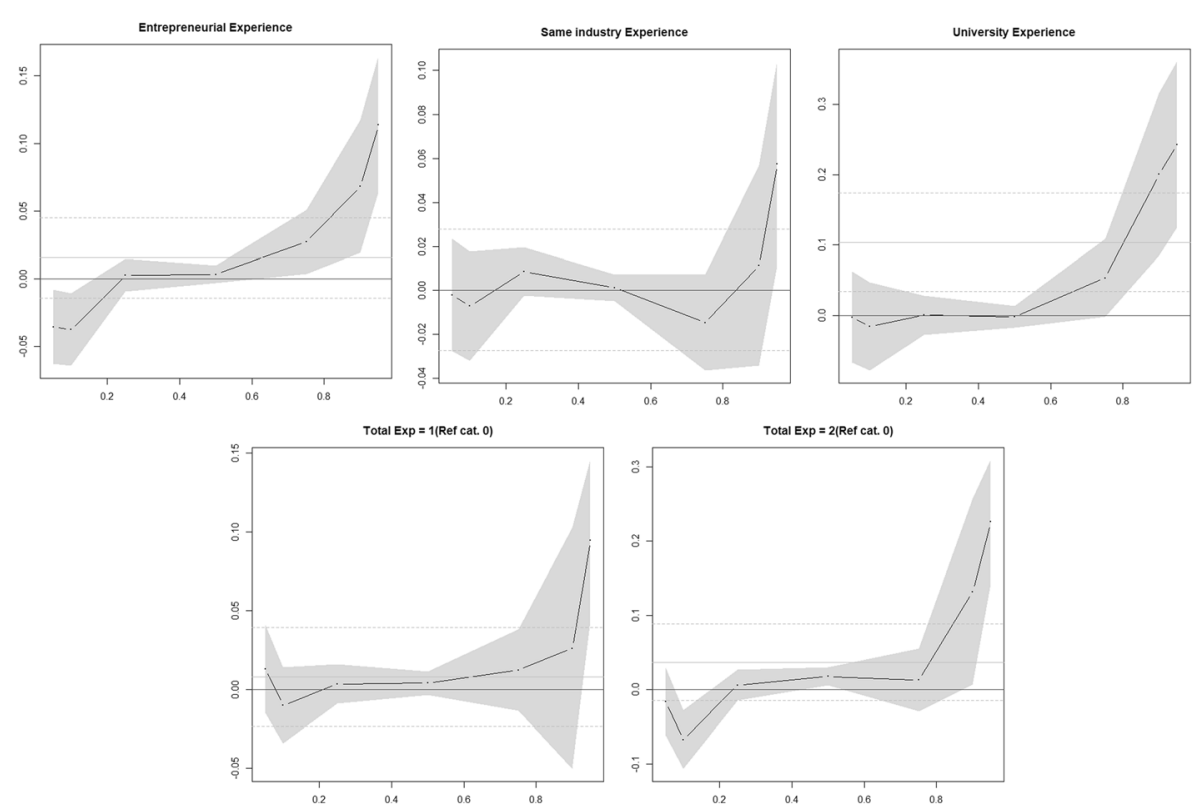

Fig. 5 Quantile plots: employee growth

was significant. These effects show that in a regression where the response variable is whether the firm achieved 'high growth' or not, these variables retained statistical significance, underlining their importance in our quantile models. Additionally, we performed the same quantile models using bootstrapped standard errors instead of IID standard errors. When performing this, only academic knowledge retained statistical
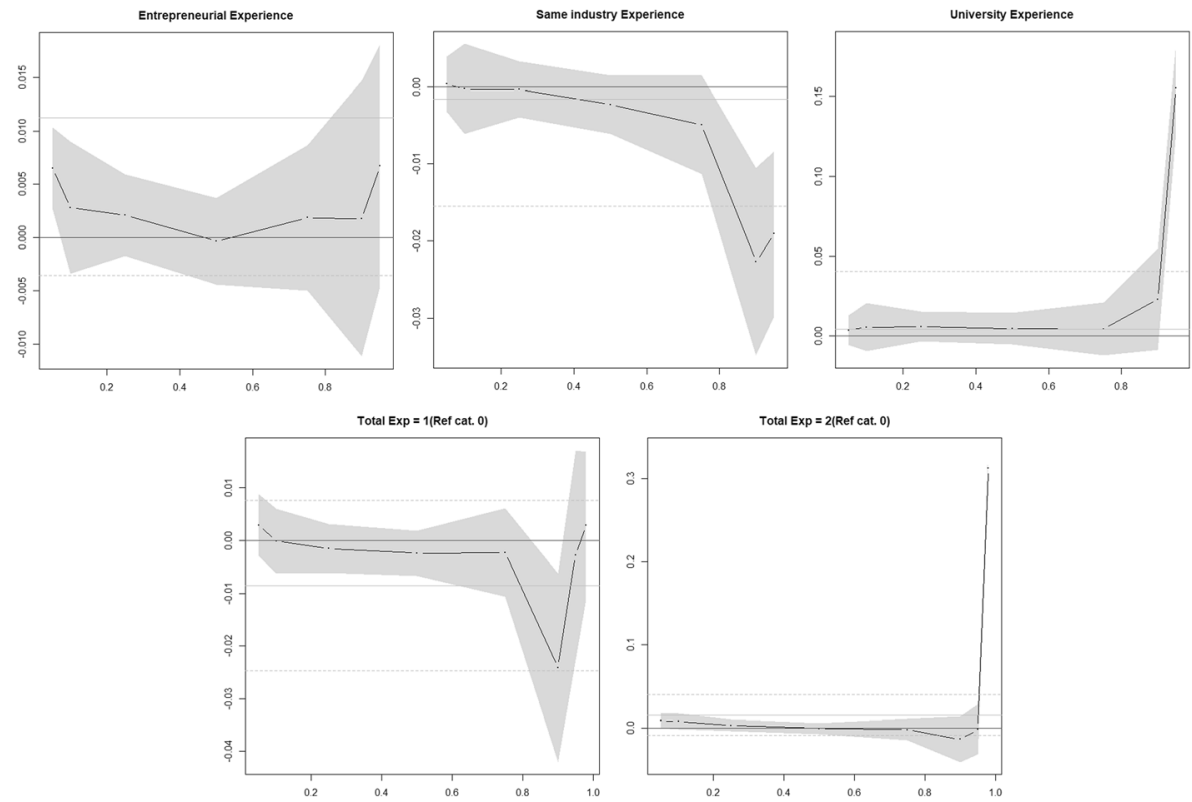

Fig. 6 Quantile plots: operating revenue growth 
significance in most cases, though the signs of the variables remained stable, which we take as a positive inclination. We also performed a 2-stage quantile regression, first computing an inverse Mills ratio, with largely comparable results.

We also performed models incorporating the effects for single founder firms: Both as an additional control variable, and by using a subsample (stratified) model containing only single founder firms. Controlling for single founders in the existing model was not statistically significant for survival or employee growth, but showed marginal positive significance $(p<.05)$ for operating revenue growth.

Regarding subsampled models for only solo founder firms, we found for only entrepreneurial experience maintained significance in our survival analysis. For employee growth we retrieved similar results to Table 8, while for operating revenue growth we found that every type of experience we study was negative in either Q90 or Q95. This could mean that solo-founded KIE firms with only one of these types of experience are somewhat disadvantaged, since they are unable to combine their unique experience with other team members, may be more at risk financially; or potentially, they require additional years of enterprising to develop the required complementary knowledge to achieve high growth in revenue.

\section{Discussion and conclusion}

Previous research on entrepreneurship from a neo-Schumpeterian approach suggests that there are specific attributes whereby these firm promote industrial transformation by combining opportunities, knowledge, and cognitive base within the firm (Metcalfe 2002; Malerba et al. 2016; Malerba and McKelvey 2018a; Cantner et al. 2017). We study performance measures in relation to both survival and high growth. In relation to knowledge-intensive innovative entrepreneurial firms, we find that the three types of founder experience differ in relation to the survival and high growth conditional upon survival. We contribute to the literature is by studying the effects of these three distinct types of experience on performance in KIE firms. Our interpretation is that these three types of founder experience - entrepreneurial, industrial and academic - suggest a variety of roles that different types of KIE entrepreneurs can play in creating opportunities, developing new knowledge that stimulates disequilibrium, and augmenting the cognitive base of the firm, in such a way as to affect selection processes in the economy. In conducting our analysis, we found associations that were not necessarily what we had initially hypothesized. We found, contrary to our predictions, that academic experience on the founding team increases the growth performance of KIE firms at the upper end of the distribution. And, having at least two types of experience present in the firm positively associates with all types of measured performance.

Firstly, our research contributes to the previous research on knowledge-intensive innovative entrepreneurship in that it demonstrates an empirical connection between founder knowledge and founder experience with the performance outcomes of KIE firms. This connection has been theoretically suggested in prior literature (Malerba and McKelvey 2018a) but has received limited empirical testing. Our results indicate that various types of founder experience each affects selection processes related to knowledge-intensive innovative entrepreneurship in different ways. Our results may help explain why KIE as a phenomenon can occur in a multitude of sectors, ranging from high-tech sectors, traditional 
and low/medium-tech sectors, and services. Across this wide spectrum of industries, we do find that founder knowledge and experience help drive survival as well as growth, but our initial results require future research to further explore the connections and explanations. We suggest that within sectors that contain KIE, academically experienced founders can team up with other types of founders, having industrial and/or entrepreneurial experience, to create stable (in terms of survival), high growth companies in the short/medium term. In essence, then, their interplay shapes whether, and to what extent, entrepreneurial actions lead to industrial transformation.

Second, our findings suggest a potentially overlooked benefit of founders possessing backgrounds within academia and scientific knowledge in traditional industries and service sectors. This extends our understanding beyond the high-tech sectors where these potential gains are known to exist. Our proposition is that the specific variety of founder knowledge and experience in KIE firms will influence which technologies and industries firms will specialize in, thereby contributing to industrial renewal. Future research could explore whether this proposition holds empirically.

Third, in terms of entrepreneurial experience, we find positive impacts both on the odds of surviving in the short to medium term, as well as - conditional on survival - on the propensity to attain high growth rates. Thus, we find that having at least one founder who has previous experience in starting up an entrepreneurial firm is also an asset for KIE firms in a way which we did not hypothesize. We suggest that previous entrepreneurial experience may be particularly important to KIE firms (even as compared to other entrepreneurial firms). Our interpretation is that entrepreneurial experience likely increases the KIE firm's capabilities in relation to specifically decisionmaking and organizational routines, in order to balance conflicting information and goals in a rapidly changing external environment (Unger et al. 2011) that surrounds knowledge-intensive and innovative entrepreneurship. Examples of KIE-related managerial decisions where entrepreneurial experience may be particular important are which product or service to focus upon, how to develop relationships to the innovation system, where to access financing, and how to benefit from public policy initiatives which all relate to innovation processes and risk taking. Because these KIE firms are often highly innovative and deal with high levels of uncertainty regarding offerings, this means that founder-managers of KIE firms must often deal with crises and transitions, and make rapid and relevant decisions, as well as revise their decisions under changing external conditions. Entrepreneurial experience could be a proxy for these types of decisions to be made, opening up trajectories of future research.

Fourth, in terms of industrial experience, our results suggest positive effects on survival but mixed results regarding high growth rates, which was overall contrary to our expectations. Specifically, KIE firms whose founders have worked in the same industry are more likely to have strong growth in employment, but not in revenue. In line with previous literature, some of the survival results may indicate that new firms rely on innovation in the 'parent' firm (Agarwal et al. 2004). Moreover, our results may be interesting and provide additional nuances to existing literature on pre-entry endowment (or heritage) literature (Klepper 2002, 2009). Founders who previously worked in the same industry often left their former employer due to disagreement about business strategy, for instance because their assessment of the potential of an innovative product or process differed (Klepper and Thompson 2010). In these cases, founder knowledge can be interpreted as underlying how the entrepreneurial firm can recognize and act upon a relevant business opportunity. 
Our results suggest that such business opportunities may help the firm survive. We suggest that KIE founders may also induce former co-workers to join the new firm, which contributes to employment growth, but not all of the identified business opportunities are substantial enough to allow for rapid growth in revenue.

Fifth, in terms of academic experience (e.g. gained from experience working at a university or research institute), we find different results for the two stages. Our interpretation is that the knowledge accrued during the founder's work at the university is likely high-level technical and scientific knowledge. In line with previous research (Zahra et al. 2007; Wennberg et al. 2011), we find no evidence that founders' academic experience enhances the odds of survival, suggesting this type of knowledge may not be very useful for the average firm. However, our findings suggest that academic experience has a positive impact on these KIE firms that are at the upper end of the growth spectrum. We propose that this reflects that some ambitious academic spinoffs maintain close ties to the university or research institute that previously employed the founder in the form of collaborations and unique assets that can be turned into capabilities, and later performance. At the same time, this is a rare event, suggesting also that for firms that do not survive, academic work experience may often not be sufficient to safeguard market implementation and successfully organize innovation within the entrepreneurial firm. Our underlying conjecture is that firms started by entrepreneurs with academic work experience are a highly heterogeneous group, an interpretation that also resonates with the finding that coefficients for this type of entrepreneurial knowledge are estimated less precisely than those of both other types of knowledge.

Lastly, we find that increased total experience from the three different types we study, entrepreneurial, intra-industry, and academic, result in increased performance in terms of both survival, and conditionally on survival, firm growth. From our results regarding firm survival, we can observe that the additive combination of entrepreneurial and industry experience enhances the survival of KIE firms; However, based on our results regarding firm growth, academic experience is positive. Therefore, we also propose that in order for these firms to excel and achieve the highest levels of growth, they may need another type of combination of prior knowledge that integrates academic experience.

\section{Limitations and future research}

Our analysis is limited by the information our data provides about the surveyed firms. We note that the original survey is of KIE firms, which are a particular type of small and medium enterprises, dependent upon knowledge and innovation to compete. The sample of KIE firms covers many sectors and countries in Europe, which, though broader than in many previous studies, is still limited in scope. Future research could replicate the survey by covering additional sectors and countries, and also collect register data. Our indicators of founder experience could also be replicated and refined in future research. Most firms in the sample do not grow, which is why we consider both survival in the population - as a measure of minimal performance - and high growth rates in employment and revenues, which characterize KIE firms at the upper end of the performance spectrum. 
Future studies should also delve further into the issue of high growth KIE firms, as well as why some such firms do not grow. More applied research could further investigate both ends of the spectrum in terms of outliers - e.g. both those showing high growth as focused upon here as well as those showing low or negative growth. Such research may yield better predictions of survival and firm performance, and could address the question: 'What prevents growth in certain KIE firms?'

Acknowledgments The authors would like to thank the participants of our paper sessions at the following: the International Schumpeter Society (ISS) annual meeting in Seoul, South Korea, July 2018; the European Association for Evolutionary Political Economy (EAEPE) annual conference in Nice, France, September 2018. Additional thanks to Linus Brunnström and the rest of our colleagues at the Institute of Innovation and Entrepreneurship, Department of Economy and Society, at the University of Gothenburg for helpful comments during paper seminars.

Funding information Open Access funding provided by University of Gothenburg. This research was supported by: the Broman Foundation for Research and Entrepreneurship Scholarship, awarded to Ethan Gifford, as part of the research project "Entrepreneurship in the New Economy: Exploring relationships between knowledge intensity, innovation and growth in new firms"; The Visiting Professor's Program at the University of Gothenburg School of Business, Economics, and Law, for their support of Guido Buenstorf; and, Swedish Research Council Distinguished Professor's Programme, awarded to Professor M. McKelvey. Research Programme: "Knowledge- intensive Entrepreneurial Ecosystems: Transforming society through knowledge, innovation and entrepreneurship", VR DNR 2017-03360.

\section{Compliance with ethical standards}

Conflict of interest The authors declare no conflicts of interest.

Open Access This article is licensed under a Creative Commons Attribution 4.0 International License, which permits use, sharing, adaptation, distribution and reproduction in any medium or format, as long as you give appropriate credit to the original author(s) and the source, provide a link to the Creative Commons licence, and indicate if changes were made. The images or other third party material in this article are included in the article's Creative Commons licence, unless indicated otherwise in a credit line to the material. If material is not included in the article's Creative Commons licence and your intended use is not permitted by statutory regulation or exceeds the permitted use, you will need to obtain permission directly from the copyright holder. To view a copy of this licence, visit http://creativecommons.org/licenses/by/4.0/.

\section{References}

AEGIS Research Project (2013) Advancing knowledge-intensive entrepreneurship and innovation for economic growth and social well-being in Europe. Grant Agreement number 225134. European Commission, DG Research, Brussels

Agarwal R, Audretsch DB (2001) Does entry size matter? The impact of the life cycle and technology on firm survival. J Ind Econ 49:21-43

Agarwal R, Shah SK (2014) Knowledge sources of entrepreneurship: firm formation by academic, user and employee innovators. Res Policy 43:1109-1133

Agarwal R, Echambadi R, Franco AM, Sarkar MB (2004) Knowledge transfer through inheritance: spin-out generation, development, and survival. Acad Manag J 47(4):501-522

Almus M, Nerlinger EA (1999) Growth of new technology-based firms: which factors matter? Small Bus Econ 13:141-154

Audretsch DB (1991) New firm survival and the technological regime. Rev Econ Stat 73:441-450

Autio E, Sapienza HJ, Almeida JG (2000) Effects of age at entry, knowledge intensity, and imitability on international growth. Acad Manag J 43(5):909-924 
Baptista R, Karaöz M, Mendonça J (2014) The impact of human capital on the early success of necessity versus opportunity-based entrepreneurs. Small Bus Econ 42:831-847

Becker GS (1964) Human capital. Columbia University Press, New York

Block JH, Fisch CO, van Praag M (2016) The Schumpeterian entrepreneur: a review of the empirical evidence on the antecedents, behaviour and consequences of innovative entrepreneurship. Ind Innov 24(1):61-95

Boeker W (1988) Organizational origins: entrepreneurial and environmental imprinting at the time of founding. In: Carrol G (ed) Ecological models of organizations. Ballinger, Cambridge, pp 33-51

Bosma N, van Praag M, Thurik R, de Wit G (2004) The value of human and social capital investments for the business performance of startups. J Small Bus Econ 23:227-236

Bracker JS, Keats BW, Pearson JN (1988) Planning and financial performance among small firms in a growth industry. Strateg Manag J 9:591-603

Brüderl J, Prisendörfer P, Zeigler R (1992) Survival chances of newly founded business organizations. Am Sociol Rev 57(2):227-242

Brush CG, Greene PG, Hart MM (2001) From initial idea to unique advantage: the entrepreneurial challenge of constructing a resource base. Acad Manag Perspect 15:64-78

Buenstorf G (2007) Evolution on the shoulders of giants: entrepreneurship and firm survival in the German laser industry. Rev Ind Organ 30:179-202

Buenstorf G, Heinisch DP (2020) Science and industry evolution: evidence from the first 50 years of the German laser industry. Small Bus Econ 54:523-538

Campbell CA (1995) An empirical test of a decision theory model for entrepreneurial acts. Entrep Reg Dev 7:95-103

Cantner U, Goethner M, Silbereisen RK (2017) Schumpeter's entrepreneur - a rare case? J Evol Econ 27(1):187-214

Carlsson B, Braunerhjelm P, McKelvey M, Olofsson C, Persson L, Ylinenpää H (2013) The evolving domain of entrepreneurship research. Small Bus Econ 41:913-930

Caves RE (1998) Industrial organization and new findings on the turnover and mobility of firms. J Econ Lit 36(4):1947-1982

Chatterji AK (2009) Spawned with a silver spoon? Entrepreneurial performance and innovation in the medical device industry. Strateg Manag J 18(1):185-206

Clarysse B, Wright M, Van de Velde E (2010) Entrepreneurial origin, technological knowledge, and the growth of spin-off companies. J Manag Stud 48(6):1420-1442

Coad A, Segarra A, Teruel M (2016) Innovation and firm growth: does firm age play a role? Res Policy 45:387-400

Cohen WM, Levinthal DA (1990) Absorptive capacity: a new perspective on learning and innovation. Adm Sci Q 35(1):128-152

Colombo MG, Grilli L (2005) Founders' human capital and the growth of new technology-based firms: a competence-based view. Res Policy 34:795-816

Colombo MG, Grilli L (2010) On growth drivers of high-tech start-ups: exploring the role of founders' human capital and venture capital. J Bus Ventur 25(6):610-626

Criaco G, Minola T, Migliorini P, Serarols-Tarrés C (2013) 'To have and have not': founders' human capital and university start-up survival. J Technol Transfer 39(4):567-593

Czarnitzki D, Delanote J (2012) Young innovative companies: the new high-growth firms? Ind Corp Chang 22(5):1315-1340

Dahl MS, Sorenson O (2014) The who, why, and how of spinoffs. Ind Corp Chang 23(3):661-688

Delmar F, Shane S (2004) Legitimating first: organizing activities and the survival of new ventures. J Bus Ventur 19:385-410

Delmar F, Wennberg K (2010) Knowledge intensive entrepreneurship: the birth, growth, and demise of entrepreneurial firms. Edward Elgar, Cheltenham

Delmar F, Davidsson P, Gartner WB (2003) Arriving at the high-growth firm. J Bus Ventur 18(2):189-216

Dencker JC, Gruber M, Shah SK (2009) Pre-entry knowledge, learning, and the survival of new firms. Organ Sci 20(3):561-537

Eriksson T, Kuhn JM (2006) Firm spin-offs in Denmark 1981-2000-patterns of entry and exit. Int J Ind Organ 24(5):1021-1040

Esteve-Peréz S, Mañez-Castillejo JA (2008) The resource-based theory of the firm and firm survival. Small Bus Econ 30:231-249

European Commission (2006) EU research on social sciences and humanities, policy and innovation in low_tech - knowledge formation, employment and growth contributions of the 'old economy' industries in Europe: pilot. RTD Publications, Brussels

European Commission (2013) Research and innovation performance in EU member states and associated countries: innovation union progress at country level. RTD Publications, Brussels

Evans DS, Jovanovic B (1989) An estimated model of entrepreneurial choice under liquidity constraints. J Polit Econ 97:806-827 
Fagerberg J (2003) Schumpeter and the revival of evolutionary economics: an appraisal of the literature. J Evol Econ 13(2):125-159

Florin J, Lubatkin M, Schulze W (2003) A social capital model of high growth ventures. Acad Manag J 46(3): 374-384

Geroski PA (1995) What do we know about entry? Int J Ind Organ 13:421-440

Gifford E (2017) Exploring knowledge intensity in entrepreneurship: a quantitative study of knowledge, innovation and performance in entrepreneurial firms. Ph. D. Dissertation. Gothenburg: University of Gothenburg

Gimeno J, Folta TB, Cooper C, Woo Y (1997) Survival of the fittest? Entrepreneurial human capital and the persistence of underperforming firms. Adm Sci Q 42(4):750-783

Hagedoorn J, Cloodt M (2003) Measuring innovative performance: is there an advantage in using multiple indicators? Res Policy 32(8):1365-1379

Haltiwanger J, Jarmin RS, Miranda J (2013) Who creates jobs? Small versus large versus young. Rev Econ Stat 95(2):347-361

Hayak FA (1945) The use of knowledge in society. Am Econ Rev 35(4):519-530

Helfat CE, Lieberman MB (2002) The birth of capabilities: market entry and the importance of pre-history. Ind Corp Chang 11(4):725-760

Henrekson M, Johansson D (2009a) Competencies and institutions fostering high-growth firms. Found Trends Entrep 5(1):1-80

Henrekson M, Johansson D (2009b) Gazelles as job creators: a survey and interpretation of the evidence. Small Bus Econ 35(2):227-244

Hitt MA, Bierman L, Shimizu K, Kochhar R (2001) Direct and moderating effects of human capital on strategy and performance in professional service firms: a resource-based perspective. Acad Manag J 44(1):13-28

Holmén M, Magnusson M, McKelvey M (2007) What are innovative opportunities? Ind Innov 41(1):27-45

Kirzner I (1973) Competition and entrepreneurship. University of Chicago Press, Chicago

Klepper S (2001) Employee startups in high-tech industries. Ind Corp Chang 10(3):639-674

Klepper S (2002) The capabilities of new firms and the evolution of the US automobile industry. Ind Corp Chang 11(4):645-666

Klepper S (2009) Spinoffs: a review and synthesis. Eur Manag Rev 6(3):159-171

Klepper S, Sleeper SD (2005) Entry by spinoffs. Manag Sci 51(8):1291-1306

Klepper S, Thompson P (2010) Disagreements and intra-industry spinoffs. Int J Ind Organ 28(5):526-538

Knight FH (1921) Risk, uncertainty and profit. Houghton Mifflin, Boston

Kor YY, Leblebici H (2005) How do interdependencies among human-capital deployment, development and diversification strategies affect firms' financial performance? Strateg Manag J 26:967-985

Lassen AH, McKelvey M, Ljungberg D (2018) Knowledge intensive entrepreneurship in creative industries as compared to manufacturing industries: same, same but different. Creat Innov Manag 27:284-294

Lazear EP (2004) Balanced skills and entrepreneurship. Am Econ Rev 94(2):208-211

Lieberman MB, Montgomery DB (2013) Conundra and progress: research on entry order and performance. Long Range Plan 46(4-5):312-324

Löfsten H, Lindelöf P (2002) Science parks and the growth of new technology-based firms - academicindustry links, innovation and markets. Res Policy 31(6):859-876

Malerba F (ed) (2010) Knowledge intensive entrepreneurship and innovation systems: evidence from Europe. Routledge, New York

Malerba F, McKelvey M (2018a) Knowledge intensive entrepreneurship: moving beyond the Schumpeterian entrepreneur. Small Business Economics, E-publication in advance of publication

Malerba F, McKelvey M (2018b) Knowledge intensive entrepreneurship and future research directions. In: Niosi J (ed) Innovation management, systems and policy. Cambridge University Press, Cambridge

Malerba F, McKelvey M (2018c) Knowledge-intensive innovative entrepreneurship. Found Trends Entrep 14(6):555-683

Malerba F, Caloghirou Y, McKelvey M, Radosevic S (eds) (2016) Dynamics of knowledge-intensive entrepreneurship: business strategy and public policy. Routledge, London

McKelvey M (2016) Firms navigating through innovation spaces: a conceptualization of how firms search and perceive technological, market and productive opportunities globally. J Evol Econ 26(4):785-802

McKelvey M, Lassen A (2013) Managing knowledge intensive entrepreneurship. Edward Elgar, Cheltenham

McKiernan P, Morris C (1994) Strategic planning and financial performance: does formality matter? Br J Strat Manag 5(1):31-41

Metcalfe JS (2002) Knowledge of growth and the growth of knowledge. J Evol Econ 12(1-2):3-15

Mudambi R, Zahra SA (2007) The survival of international new ventures. J Int Bus Stud 38(2):333-352 
Nelson RR, Winter S (1982) An evolutionary theory of economic change. Belknap Harvard, Cambridge

Parker SC (2004) The economics of self-employment and entrepreneurship. Cambridge University Press, Cambridge

Penrose E (1959) The theory of the growth of the firm. Sharpe, New York

Perkmann M, Walsh K (2007) University-industry relationships and open innovation: towards a research agenda. Int J Manag Rev 9(4):259-280

Perkmann M, Tartari V, McKelvey M, Autio E, Broström A, D'Este P, Fini R, Geuna A, Grimaldi R, Hughes A, Krabel S, Kitson M, Llerena P, Lissoni F, Salter A, Sobrero M (2013) Academic engagement and commercialisation: a review of the literature on university-industry relations. Res Policy 42(2):423-442

Pfeffer J (1994) Competitive advantage through people. Harvard Business School Press, Boston

Ployhart RE, Moliterno TP (2011) Emergence of the human capital resource: a multilevel model. Acad Manag Rev 36(1):127-150

Protogerou A, Caloghirou Y, Vonartas N (2017) Determinants of young firms' innovative performance: empirical evidence from Europe. Res Policy 46(7):1312-1326

Rickne A, Jacobsson S (1999) New technology-based firms in Sweden: a study of their direct impact on industrial renewal. Econ Innov New Technol 8(3):197-223

Sapienza H, Autio E, George G, Zahra SA (2006) The effect of early internationalization on firm profitability and growth. Acad Manag Rev 31(4):914-933

Schneider C, Veugelers R (2010) On young highly innovative companies: why they matter and how (not) to policy support them. Ind Corp Chang 19(4):1-39

Schumpeter J (1934) The theory of economic development. Harvard University Press, Cambridge

Segarra A, Callejón M (2002) New firms' survival and market turbulence: new evidence from Spain. Rev Ind Organ 20:1-14

Shane S (2000) Prior knowledge and the discovery of entrepreneurial opportunities. Organ Sci 11(4):448-469

Shane S (2003) A general theory of entrepreneurship: the individual-opportunity nexus. Edward Elgar, Northampton

Shane S, Stuart T (2002) Organizational endowments and the performance of university start-ups. Manag Sci 48:154-170

Siepel J, Cowling M, Coad A (2017) Non-founder human capital and the long-run growth and survival of high-tech ventures. Technovation 59:34-43

Smith KG, Collins CJ, Clark KD (2005) Existing knowledge, knowledge creation capability, and the rate of new product introduction in high-technology firms. Acad Manag J 48(2):346-357

Stinchcombe AL (1965) Social structure and organization. In: March JG (ed) Handbook of organizations. Rand McNally, Chicago

Strotmann H (2007) Entrepreneurial survival. Small Bus Econ 28:87-104

Tether B (2000) Small firms, innovation and employment creation in Britain and Europe. Technovation 20(2): $109-113$

Tsai W (2001) Knowledge transfer in intra-organizational networks: effects of network position and absorptive capacity on business unit innovation and performance. Acad Manag J 44(5):996-1004

Unger JM, Rauch A, Frese M, Rosenbusch N (2011) Human capital and entrepreneurial success: a metaanalytical review. J Bus Ventur 26:341-358

Visintin F, Pittino D (2014) Founding team composition and early performance of university-based spin-off companies. Technovation 34:31-43

Wennberg K, Wiklund J, Wright M (2011) The effectiveness of university knowledge spillovers: performance differences between university spinoffs and corporate spinoffs. Res Policy 40:1128-1143

Wennekers S, Thurik R (1999) Linking entrepreneurship and economic growth. Small Bus Econ 13(1):27-56

Wenting R (2008) Spinoff dynamics and the spatial formation of the fashion design industry. J Econ Geogr 8(5):593-614

Yli-Renko H, Autio E, Sapienza HJ (2001) Social capital, knowledge acquisition, and knowledge exploitation in young technology-based firms. Strateg Manag J 22(6-7):587-613

Zahra S, Van de Velde E, Larraneta B (2007) Knowledge conversion capability and the performance of corporate and university spin-offs. Ind Corp Chang 16(4):569-608

Publisher's note Springer Nature remains neutral with regard to jurisdictional claims in published maps and institutional affiliations. 